\title{
Photocatalytic Hydrophosphination with Air-Stable and Commercially Available Bis(acetylacetonato)copper(II) (Cu(acac) $\left.)_{2}\right)$
}

\author{
Steven G. Dannenberg and Rory Waterman* \\ Department of Chemistry, University of Vermont, Burlington, Vermont 05405-0125, United States
}

\begin{abstract}
Bis(acetylacetonato)copper(II) $\left(\mathrm{Cu}(\mathrm{acac})_{2}, \mathbf{1}\right)$, is active for the hydrophosphination of alkenes and alkynes with primary and secondary phosphines. Under thermal conditions, the activity of $\mathbf{1}$ is comparable to some of the best literature catalysts, but 1 is unique in that set possessing air- and water-stability. However, under ambient temperature irradiation centered at $360 \mathrm{~nm}$, the conversions are remarkable with some reactions complete in minutes and several rarely reported unactivated substrates achieving high conversions within hours. The photocatalytic conditions are critical, and comparison to literature catalysts has been made in which $\mathbf{1}$ demonstrates superior activity. Initial mechanistic work does not suggest a radical mechanism rather the formation of a copper(I) active species. Hammett analysis indicates that depending on the substrate, either a nucleophilic or insertion-based mechanism may be at work. The enhanced reactivity provided by light also appears to be generalizable to other copper(I) compounds under irradiation, representing a broader phenomenon in metal catalyzed $\mathrm{P}-\mathrm{C}$ bond formation. This simple, bench-stable, and inexpensive catalyst is highly effective, placing hydrophosphination in the hands of many more synthetic chemists.
\end{abstract}

\section{Introduction}

Metal-catalyzed hydrophosphination is a potentially powerful tool in still-challenging $\mathrm{P}-\mathrm{C}$ bond formation, despite the ubiquity of alkene substrates ${ }^{1}$ and perfect atom economy of the transformation. ${ }^{2}$ Phosphines are integral molecules in organic synthesis, catalysis, and are of importance in materials science and biologically active molecules. ${ }^{3}$ However, hydrophosphination remains the domain of specialists. Many catalysts are air- and/or water-sensitive, are complicated to prepare, or suffer from limited substrate scope or modest activity. ${ }^{4-7}$ Catalysts that are not readily available and easy to use do not augment the synthetic chemist's toolbox. ${ }^{8}$

A broadly applicable catalyst is one that also addresses some of the outstanding challenges of hydrophosphination. For example, unactivated alkene substrates remain underutilized, with limited success in a mere handful of examples. 9, 10, 11, 12, 13, 14 Webster reported an intramolecular hydrophosphination with an iron(II) $\beta$-diketiminato complex (Chart 1 , compound A) with these substrates. ${ }^{9}$ A cerium hydride metal-organic framework (Chart 1 , compound B) is capable of intermolecular hydrophosphination with diphenylphosphine and unactivated alkenes upon extended reaction times at relatively high temperature $\left(80^{\circ} \mathrm{C}\right.$ and 5 days $) .10$ Trifonov and coworkers identified calcium catalysts where the most active of them (Chart 1, compound C) capable of hydrophosphination of 1-nonene with phenylphosphine or diphenylphosphine 
in modest conversions. ${ }^{11}$ Corma reported spare conversion of 1-octene to the hydrophosphination product when treated with diphenylphosphine and $10 \mathrm{~mol} \%$ of $\mathrm{Cu}(\mathrm{OTf})_{2} \cdot$ toluene over 24 hours at $100{ }^{\circ} \mathrm{C} .12$ We have identified that zirconium compounds (Chart 1, compound D) are capable for intermolecular hydrophosphination with unactivated alkenes, which initially suffered from sluggish reactivity. ${ }^{15}$ In further investigations of this system, acceleration under photocatalytic conditions was observed, which was the critical feature for the high reactivity of triamidoamine-supported zirconium. ${ }^{13}$ Though we started with primary phosphines as substrates, ${ }^{13}, 16$ photocatalytic conditions availed a broader swath of substrates including secondary phosphines at reasonable reaction times at ambient temperature. ${ }^{14}$ Substrate challenges dovetail into activity, and good progress has been made by Sarazin with barium ${ }^{17}$ and ytterbium ${ }^{18}$ catalysts at ambient conditions, but these are limited to styrene as substrate. Highly substituted alkenes still remain a challenge for catalytic hydrophosphination, though great progress has been made with stilbene by each Trifonov ${ }^{19}$ and Cui. ${ }^{20}$ It is easy to understand how these challenges would thwart better utilization of hydrophosphination in the synthetic community, despite the ubiquity of alkenes. The use of hydrophosphination in routine synthesis requires readily available, inexpensive catalysts that have established reactivity with a wide range of substrates.

\section{Chart 1: Examples of hydrophosphination catalysts that are active with unactivated alkenes}

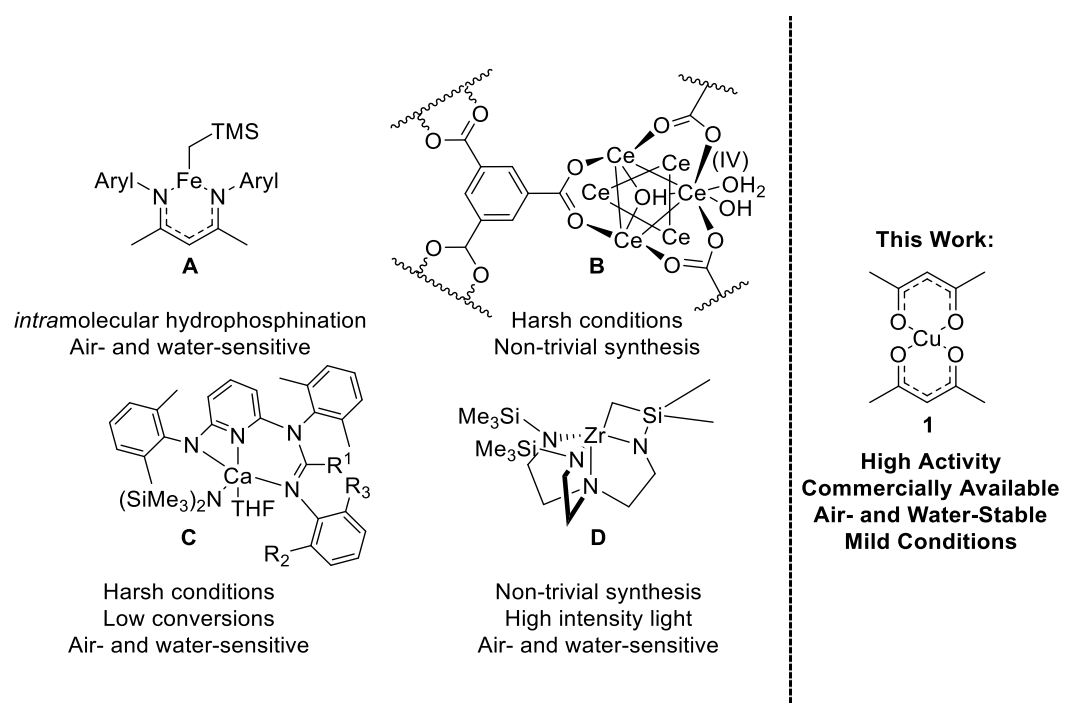

Therefore, a search for a highly active, commercially available, air-stable, and base metal hydrophosphination catalyst was undertaken. Such a catalyst would allow hydrophosphination to become a more commonplace and synthetically usefully reaction for exploitation in late stage diversification of organic molecules. Beyond the preparation of $\mathrm{P}(\mathrm{III})-\mathrm{C}$ bonds, simple oxidation of products would also afford $\mathrm{P}(\mathrm{V})-\mathrm{C}$ bond as well, allowing for a greater range of bioactive products. The synthetic convenience of a single reaction to access both oxidation states of phosphorus is undeniable, and such a strategy leverages the order of magnitude lower cost of the secondary phosphine as precursor..$^{21}$ 
Among base metals, iron is ideal. It has been the subject of on-going study in our hands 22,23 and others' to good effect.9, 24-28, 29 The criteria above, though, are yet to be fully met by iron, leading to an expanded search. Copper is a desirable metal due to its recyclability, relative abundance, low toxicity, and the air- and water-stability of many precursors that allow for easy handling. ${ }^{30,31}$ Based on literature studies, $\mathrm{Cu}$ (acac)2 (1) was identified as an ideal candidate for our studies. Hydrophosphination of alkynes has been achieved by Oshima and coworkers with copper(I) iodide with cesium carbonate 32 and by Cui and coworkers using N-heterocyclic carbene (NHCs) ligands. ${ }^{33}$ Hydrophosphination with a range of copper salts has been reported by Corma, which revealed that $\mathrm{Cu}(\mathrm{OTf})_{2}, \mathrm{CuCl}_{2}$, and $\mathrm{CuCl}$, all catalyze the hydrophosphination of styrene derivatives with secondary phosphines at elevated temperatures and extended reaction times. ${ }^{12}$ The Lipshutz group improved upon this copper catalysis by demonstrating hydrophosphination of $\alpha$-substituted styrene derivatives and $\mathrm{Ph}{ }_{2} \mathrm{PH}$ using $\mathrm{Cu}(\mathrm{OAc})_{2} \cdot \mathrm{H}_{2} \mathrm{O}(2)$ in water and with the surfactant TPGS-750-M.34 This study indicated that greater reactivity could be realized with copper. We hypothesized that photocatalysis may enhance reactivity to provide high reactivity and a broader substrate scope.

At the same time, copper bis(diketonato) compounds are effective in group 15 bond activation reactions with several examples of $\mathrm{N}-\mathrm{H}$ activation in Ullman-type reactions and $\mathrm{C}-\mathrm{N}$ coupling reactions. ${ }^{35-39}$ Several groups have found $\mathbf{1}$ to be more effective at $\mathrm{C}-\mathrm{H}$ amination reactions compared to other copper salts, ${ }^{36,37}$ and Beletskaya also demonstrated that 1 was an active catalyst for P-H bond activation and addition to alkynes with phosphorous(V) substrates. ${ }^{40}$

The sum of this analysis lead to the general hypothesis that highly successful hydrophosphination reactivity can be achieved by employing 1 as a pre-catalyst. This hypothesis has borne out, and herein is reported the substantial activity of 1 under $360 \mathrm{~nm}$ irradiation at ambient temperature. This overall high activity is accompanied by a significant substrate scope of alkenes and alkynes. For many substrates in this system, activity rivals or surpasses the activity of previous hydrophosphination reports with any metal and catalyst system. In this regard, $\mathbf{1}$ achieves the aim of an easy-to-use, highly active, and readily available hydrophosphination catalyst.

\section{Results and Discussion Optimization of Conditions}

Hydrophosphination of styrene was examined first due to its common use in recent studies. ${ }^{41,42,43,44} \mathrm{~A}$ chloroform- $d_{1}$ solution of styrene was treated with 2 equiv. of phenylphosphine in the presence of 5 mol $\%$ of $\mathbf{1}$. The mixture was irradiated with a broad wavelength 9-W UV/A lamp (see SI for details) at ambient temperature for 20 min, resulting in complete consumption of styrene as measured by ${ }^{1} \mathrm{H}$ NMR spectroscopy and $91 \%$ conversion to the anti-Markovnikov, single activation product $\mathrm{PhPHCH} 2 \mathrm{CH}_{2} \mathrm{Ph}$ as determined by ${ }^{31} \mathrm{P}\left\{{ }^{1} \mathrm{H}\right\}$ NMR spectroscopy (Scheme 1 ). Reactions with primary phosphines are often run with excess phosphine to minimize the double activation product, and indeed, small amounts of 
the tertiary phosphine with similarly limited amounts of 1,2-diphenyldiphosphine were observed. These byproducts and catalyst were readily separated by chromatography to afford product in $66 \%$ isolated yield. Isolation of phosphine products in these reactions is well described. $16,34,45$

Scheme 1. Initial hydrophosphination of styrene with phenylphosphine by $\mathbf{1 .}$

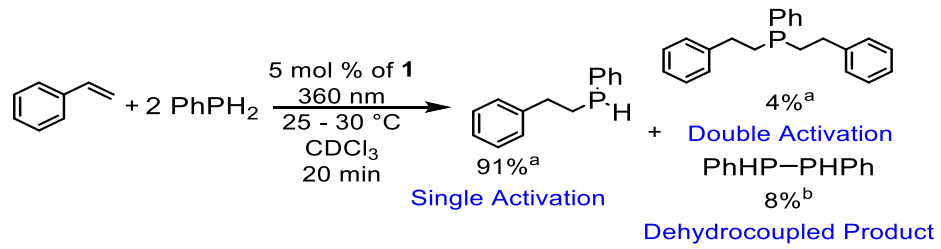

[a] conversion of styrene determined by ${ }^{1} \mathrm{H} N M R$ and ${ }^{31} \mathrm{P}\left\{{ }^{1} \mathrm{H}\right\}$ NMR spectroscopy of three trials and integration to internal standard of $1,3,5$,trimethoxybenzene (See SI for note on determination of yields) ${ }^{[b]}$ conversion of phosphine determined by ${ }^{31} \mathrm{P}\left\{{ }^{1} \mathrm{H}\right\} \mathrm{NMR}$ spectroscopy.

Initial screening demonstrated that secondary phosphines are also viable substrates. Treatment of styrene and 1 equiv., of diphenylphosphine with 5 mol \% of 1 resulted in $85 \%$ conversion to $\mathrm{Ph}_{2} \mathrm{PCH}_{2} \mathrm{CH}_{2} \mathrm{Ph}$ as measured by ${ }^{1} \mathrm{H}$ and ${ }^{31} \mathrm{P}\left\{{ }^{1} \mathrm{H}\right\}$ NMR spectroscopy after $5 \mathrm{~h}$ of $360 \mathrm{~nm}$ irradiation and 95\% conversion was observed after $24 \mathrm{~h}$ of irradiation.

Scheme 2. Initial hydrophosphination of styrene with diphenylphosphine by $\mathbf{1}$.

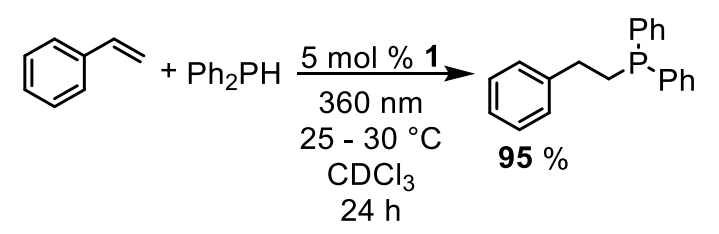

Several control reactions were then conducted in the reaction of 2 equiv. of phenylphosphine and styrene (Table 1). Under $360 \mathrm{~nm}$ irradiation in the absence of 1, only $6 \%$ conversion was observed at $20 \mathrm{~min}$, compared to $91 \%$ (vide supra). Reactions run in ambient light, at $60{ }^{\circ} \mathrm{C}$ with $5 \mathrm{~mol} \%$ of 1 , went to $59 \%$ completion when measured at 20 min of heating, 79\% after $45 \mathrm{~min}$, and 90\% after $75 \mathrm{~min}$. For comparison, the temperature of the 360 nm photoreactor was measured to be $25-30{ }^{\circ} \mathrm{C}$, depending on how long it had been in use. No efforts to control the temperature within this range were undertaken. 
Table 1. Optimization of Conditions

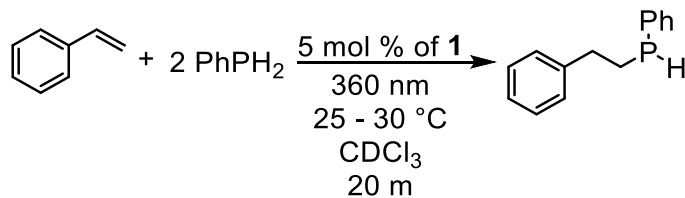

\begin{tabular}{lll} 
Entry & Deviation from standard conditions & Conversion (\%) \\
1 & None & 100 \\
2 & 1 eq PhPH 2 & 51 \\
3 & Control; without 1 & 6 \\
4 & Ambient light, $60^{\circ} \mathrm{C}$ & 59 \\
5 & Visible Light LED & 45 \\
6 & Ambient light & 15 \\
7 & Dark & 7 \\
8 & 2 mol \% of $\mathbf{1}$ & 100 \\
9 & 1 mol \% of $\mathbf{1}$ & 90 \\
10 & 25 mol \% of $\mathbf{1}$ & 40 \\
11 & Neat & 100 \\
12 & Benzene- $d_{6}$ solution & 100 \\
\hline
\end{tabular}

Standard condition: $0.38 \mathrm{mmol}(39.5 \mathrm{mg}$ ) of styrene and 0.76 mmol phenylphosphine $(83.5 \mathrm{mg}$ ) and $0.19 \mathrm{mmol}(5 \mathrm{mg})$ of $\mathbf{1}$ in $600 \mu \mathrm{L}$ of $\mathrm{CDCl}_{3}$. Changes in catalyst loading and phenylphosphine equivalents are with respect to styrene. Conversion to both secondary and tertiary phosphine determined by integration of ${ }^{1} \mathrm{H}$ and ${ }^{31} \mathrm{P}\left\{{ }^{1} \mathrm{H}\right\}$ NMR spectra.

Exploration of a wavelength dependence was undertaken with the phenylphosphine reaction at 5 mol \% loading of 1 (Figure 1). Irradiation with visible light using a commercial LED bulb resulted in 100\% conversion of styrene and $96 \%$ selectivity for the single activation hydrophosphination product $\mathrm{PhPHCH}_{2} \mathrm{CH}_{2} \mathrm{Ph}$ in less than $2 \mathrm{~h}$. Reactions under ambient light at ambient temperature proceeded to $15 \%$ completion in $20 \mathrm{~min}, 60 \%$ at $2 \mathrm{~h}$, and $100 \%$ conversion of styrene with 96\% selectivity for $\mathrm{PhPHCH}_{2} \mathrm{CH}_{2} \mathrm{Ph}$ in less than $7 \mathrm{~h}$. Reactions run in the dark resulted in only $7 \%$ conversion of styrene after $20 \mathrm{~min}, 42 \%$ after $18 \mathrm{~h}$, and $58 \%$ after $44 \mathrm{~h}$.

The photocatalytic nature of the reaction was established with an initiation experiment. A two-to-one mixture of phenylphosphine and styrene with $5 \mathrm{~mol} \%$ of 1 was irradiated at $360 \mathrm{~nm}$ for a 3-minute interval and otherwise kept in the dark. After an initial 12 min with no irradiation, 4\% conversion was measured by ${ }^{1} \mathrm{H}$ NMR spectroscopy. Then, following 3 min of irradiation, $28 \%$ conversion was measured. Subsequent monitoring of the reaction revealed nearly identical conversation after an additional 25 min in the dark, and the conversion only rose to $41 \%$ after 3 additional hours in the dark. The fast formation of product in the light that slows in the dark indicates that the reaction is photocatalytic rather than photoinitiated. Both behaviors have been observed for hydrophosphination catalysts. ${ }^{13,}$ 23, 46 
Figure 1. Light dependence of hydrophosphination of styrene with phenylphosphine by $\mathbf{1}$.

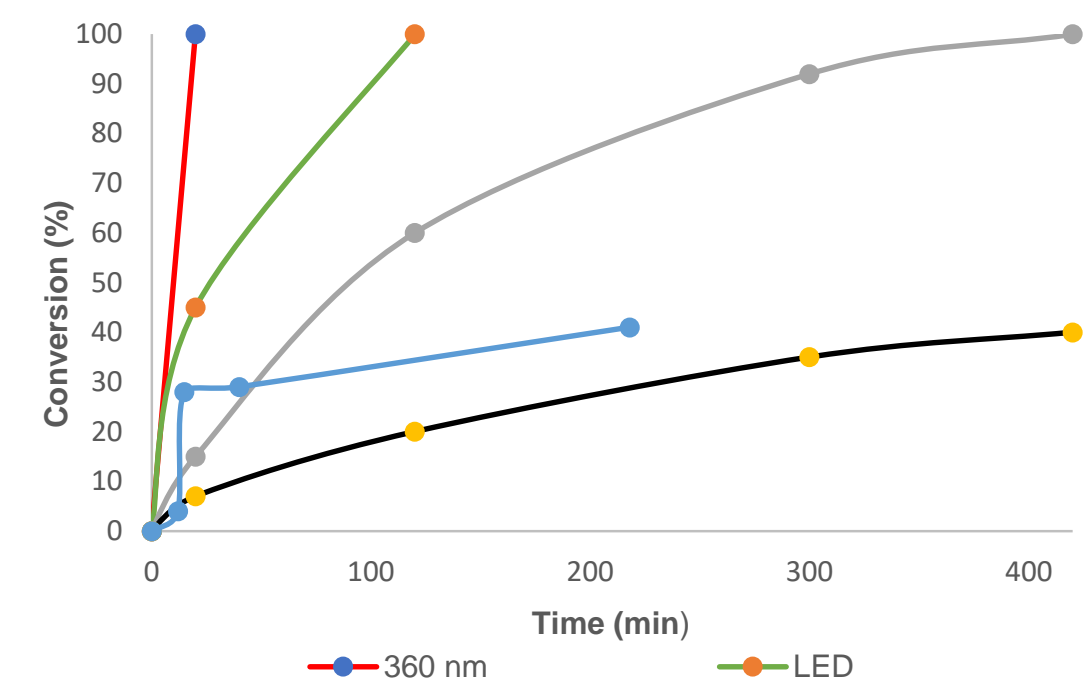

Standard conditions: $0.38 \mathrm{mmol}(39.5 \mathrm{mg})$ of styrene and $0.76 \mathrm{mmol}$ phenylphosphine $\left(83.5 \mathrm{mg}\right.$ ) and $0.19 \mathrm{mmol}(5 \mathrm{mg})$ of 1 in $600 \mu \mathrm{L}$ of $\mathrm{CDCl}_{3}$.

Several catalyst loadings were then tested for the hydrophosphination of styrene with two equivalents of phenylphosphine (Table 2). Complete consumption of styrene was achieved with $2 \mathrm{~mol} \%$ of $\mathbf{1}$. Decreasing the loading to 1 mol $\%$ of 1 resulted in $90 \%$ consumption of styrene and 79\% NMR conversion of $\mathrm{PhPHCH}_{2} \mathrm{CH}_{2} \mathrm{Ph}$. When the catalyst loading was increased to $25 \mathrm{~mol} \%, 40 \%$ conversion of styrene was measured after $20 \mathrm{~min}$ of $360 \mathrm{~nm}$ irradiation. The non-linear dependence on catalyst is consistent with dimeric, oligomeric, or polymeric aggregation of catalyst, which is common for copper hydride and copper phosphide complexes. ${ }^{47,48}$ It also may be the result of a decreased relative concentration of phenylphosphine, an idea explored in further detail with additional mechanistic experiments.

Despite comparable activity with $2 \mathrm{~mol} \%$ of catalyst, $360 \mathrm{~nm}$ irradiation with $5 \mathrm{~mol} \%$ of $\mathbf{1}$ was used for ease of benchmarking with literature reports. It is recommended that new utilization of $\mathbf{1}$ should be initiated at $2 \mathrm{~mol} \%$ and loadings increased if the substrates prove challenging. Similarly, reactions were run in chloroform- $d$ as opposed to neat or in benzene- $d_{6}$ despite similar reactivity, due to ease of monitoring by ${ }^{1} \mathrm{H}$ NMR spectroscopy.

\section{Hydrophosphination of styrene derivatives}

Treatment of para-substituted styrenes bearing electron withdrawing or donating substituents were amenable to these conditions and converted to the respective secondary phosphine product in $>90 \%$ in 20 min when treated with 2 equiv. of phenylphosphine under $360 \mathrm{~nm}$ irradiation (Table 2, products 3a-e). Similarly, 2-vinyl pyridine (Table 2 product 3f) was amenable to these conditions. When these substrates were treated with 1 equiv. of diphenylphosphine, the tertiary 
phosphine products were formed in good to excellent yields in under $5 \mathrm{~h}$ with $>90 \%$ conversion in less than $24 \mathrm{~h}$ (Table 2 , products $\mathbf{3 g - k}$ ). Under these conditions, it was not empirically obvious that either electron donating or withdrawing substituents promote the reaction for either phenyl- or diphenylphosphine.

More sterically encumbered styrenes are accessible in this system as well. A cis/trans mixture of $\beta$-methylstyrene treated with phenylphosphine and 1 under irradiation resulted in 99\% conversion in 20 h to previously unreported 31. The trans isomer does appear to go to completion faster, and it is unclear whether this is due to isomerization or steric factors. Treatment of $\alpha$-methyl styrene and phenylphosphine with $\mathbf{1}$ under irradiation resulted in $92 \%$ conversion to $\mathbf{3 m}$ in just over $2 \mathrm{~h}$. When $\alpha$-methyl styrene was treated with diphenylphosphine, $63 \%$ conversion to product $\mathbf{3 n}$ was measured at 21 h. Increasing the amount of diphenylphosphine to 1.5 equiv. per alkene resulted in $83 \%$ conversion after $20 \mathrm{~h}$ of irradiation and indicates a possible dependence on phosphine concentration in the reaction. Additionally, 1.5 equiv. of diphenylphosphine was used in Lipshutz's study, which allowed for a comparison of copper catalysts and is discussed in a subsequent section. ${ }^{34}$

Phosphines with substituents other than phenyl, though not commonly reported, ${ }^{4,11,49}$, are viable in this system (Table 2, products 3o-3p). Treatment of styrene with 2 equiv. of mesitylphosphine in the presence of 5 mol \% of $\mathbf{1}$ gave quantitative conversion to product 30 within 20 min, a more than 70 fold increase over previous reports. ${ }^{11,13}$ Reaction of 2 equiv. of cyclohexylphosphine with styrene and 5 mol \% of $\mathbf{1}$ proceeded to $46 \%$ conversion to product $\mathbf{3 p}$ after $28 \mathrm{~h}$ of $360 \mathrm{~nm}$ irradiation. The difference in reactivity suggests electronic factors play a role but steric factors confound that assessment. 
TABLE 2. Hydrophosphination of styrene derivatives

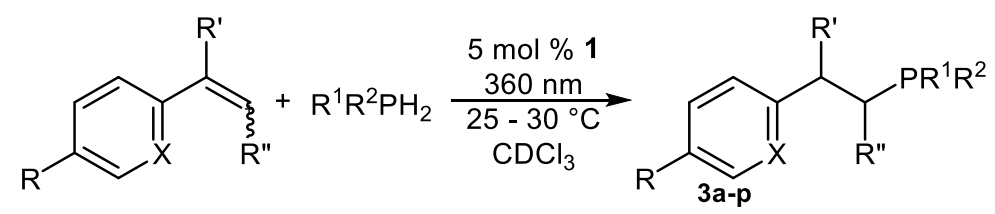

Substrate Scope: phenylphosphine with styrene derivatives ${ }^{a}$<smiles>c1ccc(CPc2ccccc2)cc1</smiles>

$3 a$

$100 \%{ }^{c}$

$91 \%$ d,e,f $(66)^{\mathrm{g}}$

$20 \mathrm{~m}$<smiles>Cc1ccc(CCPc2ccccc2)cc1</smiles>

3b

$100 \%$ c

$91 \% \mathrm{~d}$, e

$25 \mathrm{~m}$<smiles>CC(C)(C)c1ccc(CPc2ccccc2)cc1</smiles>

$3 \mathbf{c}$
$100 \%^{c}$
$94 \%^{\mathrm{e}}$
$20 \mathrm{~m}$<smiles>Brc1ccc(CPc2ccccc2)cc1</smiles>

3d

$100 \%$ c

$94 \% \mathrm{e}^{\mathrm{e}}$

$20 \mathrm{~m}$<smiles>FC(F)(F)c1ccc(CPPc2ccccc2)cc1</smiles>

$3 \mathbf{e}$

$100 \%{ }^{\mathrm{c}}$

$96 \% \mathrm{e}^{\mathrm{e}}$

$20 \mathrm{~m}$ 3f

$100 \%{ }^{c}$

$86 \% \mathrm{e}^{\mathrm{e}}$

$20 \mathrm{~m}$

Substrate Scope: diphenylphosphine with styrene derivatives ${ }^{b}$<smiles>c1ccc(CP(c2ccccc2)c2ccccc2)cc1</smiles>

$3 \mathbf{g}$
$85 \% \mathrm{e}, \mathrm{f}$

$5 \mathrm{~h}$<smiles>Cc1ccc(CP(c2ccccc2)c2ccccc2)cc1</smiles>

$3 \mathbf{h}$ $98 \% \mathrm{e}^{\mathrm{e}}$

$5 \mathrm{~h}$<smiles>CC(C)(C)c1ccc(CP(c2ccccc2)c2ccccc2)cc1</smiles>

$3 \mathbf{i}$

$83 \%$ d, e

$5 \mathrm{~h}$<smiles>Brc1ccc(CP(c2ccccc2)c2ccccc2)cc1</smiles>

3j $88 \% \mathrm{e}^{\mathrm{e}}$ $5 \mathrm{~h}$<smiles>FC(F)(F)c1ccc(CP(c2ccccc2)c2ccccc2)cc1</smiles>

$3 \mathbf{k}$ $87 \%{ }^{\mathrm{e}}$

$5 \mathrm{~h}$

\section{Substrate scope: $\alpha / \beta$ substituted styrenes}<smiles>C[C@@H](Cc1ccccc1)Pc1ccccc1</smiles>

\section{1}

$99 \%$ a, e

$20 \mathrm{~h}$<smiles>CC(CPc1ccccc1)c1ccccc1</smiles>

$3 \mathbf{m}$

$92 \%{ }^{a}$ e

2h $15 \mathrm{~m}$<smiles>CC(CP(c1ccccc1)c1ccccc1)c1ccccc1</smiles>

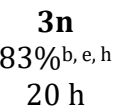

Substrate scope: primary phosphines $^{a}$

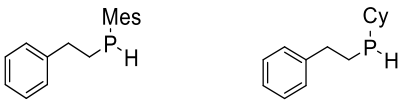

$\begin{array}{cc}\text { 3o } & \text { 3p } \\ 96 \% \mathrm{e} & 46 \% \mathrm{e}^{\mathrm{e}} \\ 20 \mathrm{~m} & 28 \mathrm{~h}\end{array}$

[a] $0.38 \mathrm{mmol}$ unsaturated substrate and $0.76 \mathrm{mmol}$ phenylphosphine [b] $0.38 \mathrm{mmol}$ unsaturated substrate and $0.38 \mathrm{mmol}$ diphenylphosphine [c] conversion of styrene starting material to secondary or tertiary hydrophosphination product by ${ }^{1} \mathrm{H}$ NMR spectroscopy [d] conversion of hydrophosphination product as determined by comparison to internal standard of 1,3,5,- trimethoxybenzene or TMS [e] conversion determined by integration of ${ }^{1} \mathrm{H}$ and ${ }^{31} \mathrm{P}\left\{{ }^{1} \mathrm{H}\right\}$ NMR spectra for starting material to products (See SI for note on determination of yields) [f] average of three trials [g] isolated yield [h] 1.5 eq phosphine used $(0.375$ phosphine, $0.25 \mathrm{mmol}$ unsaturated, $5 \mathrm{~mol} \%$ of $\mathbf{1}$ )

\section{Unactivated alkene substrates}

Unactivated alkenes are a significant challenge and were explored next (Table 3). Treatment of terminal alkenes such as 1 -hexene and 1-octene with 2 equiv. of phenylphosphine and 5 mol \% of $\mathbf{1}$ gave greater than $70 \%$ conversion to the single activation, secondary phosphine product when monitored by ${ }^{31} \mathrm{P}\left\{{ }^{1} \mathrm{H}\right\}$ and ${ }^{1} \mathrm{H}$ NMR over $16 \mathrm{~h}$ or fewer under irradiation at $360 \mathrm{~nm}$ (products $\mathbf{4 a}$ and $\mathbf{4 b}$ ). This is the fastest report of these substrates with primary phosphines to date.11, 13 The only other report with a comparable yield is our previous report with zirconium under photolysis from a higher intensity $253.7 \mathrm{~nm} \mathrm{Hg}$ arc lamp for $24 \mathrm{~h} .{ }^{13}$ Reaction with ethoxy ethene gave $81 \%$ conversation to product $4 \mathrm{c}$ in $6 \mathrm{~h}$, again the fastest and highest conversion observed to date. ${ }^{13}$ Unactivated cyclic internal alkenes such as cyclohexene and cis- 
cyclooctene were unreactive under these conditions. Reticence of such substrates has been observed in other coppercatalyzed reactions, which has been attributed to an increased barrier to insertion. ${ }^{50}$

Secondary phosphines were more sluggish with these alkenes. Efficient conversion of these substrates has yet to be achieved without elevated temperatures and 3-5 days of reaction time.10-12, 14 Treatment of 1-hexene with diphenylphosphine and $5 \mathrm{~mol} \%$ of $\mathbf{1}$ under irradiation at $360 \mathrm{~nm}$ gave less than $20 \%$ conversion after 24 h. However, irradiation of a neat mixture of 1-hexene, and increasing to three equivalents of diphenylphosphine, and 5 mol \% of 1 for $24 \mathrm{~h}$ resulted in $74 \%$ conversion to product $\mathbf{4 d}$ as determined by ${ }^{1} \mathrm{H}$ and ${ }^{31} \mathrm{P}\left\{{ }^{1} \mathrm{H}\right\}$ NMR spectroscopy. NMR spectra of this reaction mixture were broad, and crude separation from copper was performed for firm characterization of the tertiary phosphine product. Consistent with other studies, neat reactions can be more effective with 1.11,22, 26

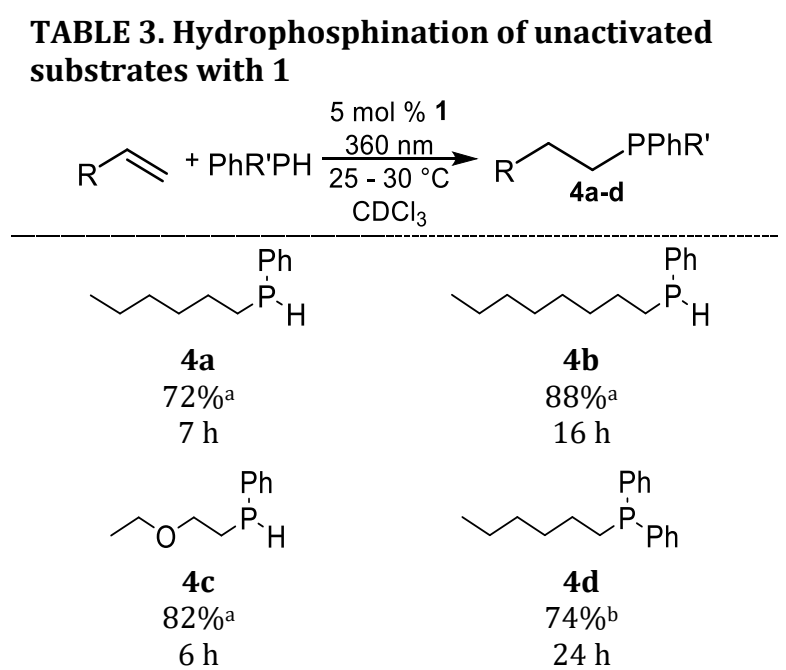

Conversions determined by integration of ${ }^{1} \mathrm{H}$ and ${ }^{31} \mathrm{P}\left\{{ }^{1} \mathrm{H}\right\}$ NMR spectra [a] $0.38 \mathrm{mmol}$ unsaturated substrate and $0.76 \mathrm{mmol}$ phosphine [b] neat with 0.38 mmol 1-hexene and $0.114 \mathrm{mmol} \mathrm{Ph}_{2} \mathrm{PH}$

\section{Other common hydrophosphination substrates}

Several of the other frequently utilized unsaturated substrates were also tested (Table 4). Reaction of 2,3dimethyl,1-3-butadiene afforded the 1,4-addition product within 80 min with phenylphosphine (product $\mathbf{5 a}$ ) and $8 \mathrm{~h}$ with diphenylphosphine (product $\mathbf{4 b}$ ) under photocatalytic conditions with 5 mol \% of $\mathbf{1}$. All Michael acceptors tested reacted rapidly with both phenyl- and diphenylphosphine (products 5c-e). Initial NMR spectra obtained before irradiation indicated that full conversion methyl acrylate and acrylonitrile had occurred. While these activated alkenes are generally facile hydrophosphination substrates, uncatalyzed reactions are typically on the order of hours at elevated temperatures which was confirmed in control experiments without copper. Similarly, reactions at ambient temperatures with the best 
literature catalysts generally proceed over the course of an hour ${ }^{51}$ or more. ${ }^{29,52}$ A strained internal alkene, norbornene, gave $99 \%$ conversion as determined by ${ }^{1} \mathrm{H}$ NMR spectroscopy and $96 \%$ conversion as determined by ${ }^{31} \mathrm{P}\left\{{ }^{1} \mathrm{H}\right\}$ NMR spectroscopy (5f). Although not a common hydrophosphination substrate, allyl chloride proceeds in $63 \%$ conversion to $\mathbf{5 g}$ and further illustrates the functional group tolerance of this catalyst.

\section{Table 4. Hydrophosphination of other common} hydrophosphination substrates

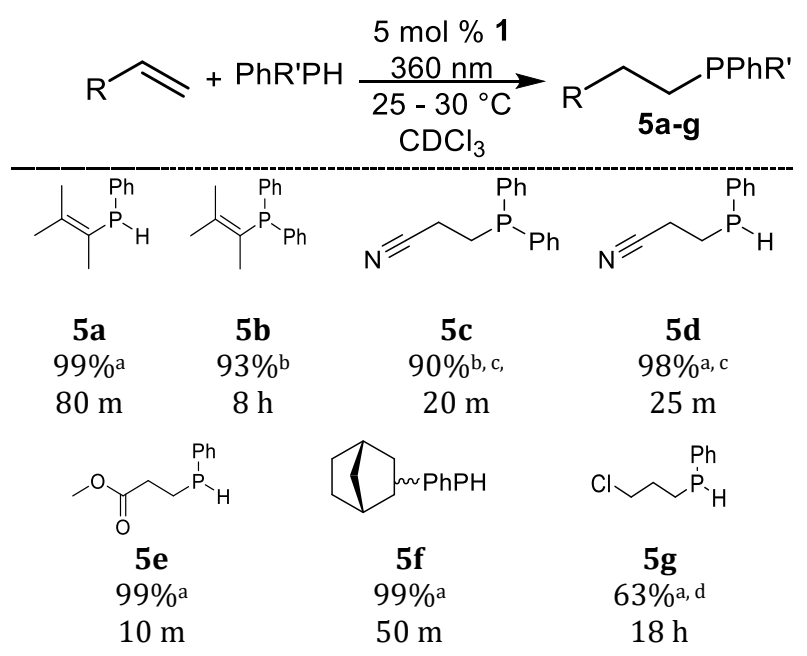

Yields determined by integration of ${ }^{1} \mathrm{H}$ and ${ }^{31} \mathrm{P}\left\{{ }^{1} \mathrm{H}\right\}$ NMR spectra [a] $0.38 \mathrm{mmol}$ of unsaturated substrate and 0.76 mmol of phenylphosphine [b] $0.38 \mathrm{mmol}$ unsaturated substrate and $0.38 \mathrm{mmol}$ diphenylphosphine [c] ambient light [d] yield determined by integration to internal standard of TMS

\section{Alkyne substrates}

Treatment of internal and terminal alkynes under irradiation with either phenyl- or diphenylphosphine provided access to vinyl phosphine products (Table 5, entries 1-12). Reaction of 1-phenyl-1-butyne with 1 equiv. of phenylphosphine and $5 \mathrm{~mol} \%$ of 1 under $360 \mathrm{~nm}$ irradiation for $24 \mathrm{~h}$ afforded the vinyl phosphine product in $81 \%$ conversion with $100 \%$ selectivity for P-C bond formation at the alkyl substituted position and a 3:1 preference for the Z-isomer (Table 5, entry 1). Reaction with 2 equiv. of phenylphosphine under the same conditions afforded the vinyl phosphine product in nearly quantitative conversion and 2.45:1 selectivity (Table 5, entry 2). Under both conditions, only trace amounts of the double hydrophosphination product were observed, 22,33,53-56 but this reaction was not pursued further.

Symmetrical alkenes such as 3-hexyne and diphenylacetylene, proceed in poor yield with one equivalent of phenylphosphine and moderate yields with two equivalents of phenylphosphine under irradiation with 5 mol \% of 1 (Table 5, entries 3-6). The stereoselectivity for these reactions were opposite, where 3-hexyne gave slight selectivity for the $E$ isomer while diphenylphosphine moderately favored the $Z$-isomer. 
Different reactivity was observed when terminal alkynes such as phenylacetylene were treated with 2 equiv. of phenylphosphine, which resulted in activation of both P-H bonds to form tertiary divinyl phosphines with a 3:1 selectivity for the $Z, Z$ isomer over the $E, Z$ isomer (Table 5, entry 7). Reducing the amount of starting phosphine to 0.5 equivalents affords $92 \%$ conversion in $20 \mathrm{~h}$ with nearly identical selectivity for the $Z, Z$ isomer (Table 5, entry 8).

Reaction of a 1:1 mixture of diphenylphosphine and phenyl-1-butyne with $5 \mathrm{~mol} \%$ of 1 under $360 \mathrm{~nm}$ irradiation for $24 \mathrm{~h}$ resulted in $74 \%$ conversion with $100 \%$ selectivity for $\mathrm{P}-\mathrm{C}$ bond formation at the alkyl substituted position and a 4.8:1 preference for the $E$-isomer (Table 5, entry 9). However, the Z:E selectivity appears to be variable as a replication of this reaction under identical conditions resulted in 75\% conversion but 1:1.1 selectivity. This behavior has been observed before and could be attributable to $\mathrm{UV}^{4}$ or on metal isomerization. ${ }^{57}$ Yields can be improved by using excess phosphine as demonstrated with phenylacetylene which goes to $41 \%$ completion when treated with 1 equiv. of diphenylphosphine and 77\% completion when treated with 2 equiv. (Table 5, entry 10 and 11 ).

Diphenylacetylene proceeded poorly with 1 equiv. of phenylphosphine reaching $12 \%$ conversion after 24 h (Table 5, entry 12). When the above reaction was run with $5 \mathrm{~mol} \%$ of $\mathrm{PPh}_{3}$, a trivial difference was observed over $24 \mathrm{~h}$ (Table 5 , entry 13). Added $\mathrm{PPh}_{3}$ has improved copper catalysis in other systems. ${ }^{58,59}$ Modest improvements could also be made by running the reaction neat (Table 5, entry 14) or by adding a second equivalent of diphenylphosphine with a longer reaction time. Reactions run with 2 equiv. of diphenylphosphine reached $19 \%$ conversion after $20 \mathrm{~h}$ and $36 \%$ conversion after $72 \mathrm{~h}$ (Table 5, entry 14).

\begin{tabular}{|c|c|c|c|c|c|c|}
\hline \multicolumn{7}{|c|}{ TABLE 5. Hydrophosphination of alkynes } \\
\hline $\mathrm{R}=$ & $-R^{\prime}$ & $P$ & \multicolumn{2}{|c|}{$\begin{array}{c}5 \mathrm{~mol} \% \text { of } 1 \\
360 \mathrm{~nm} \\
\underset{25-30{ }^{\circ} \mathrm{C}}{\mathrm{CDCl}_{3}} \\
24 \mathrm{~h}\end{array}$} & $\mathrm{R}^{N} \mathrm{Y}^{\mathrm{PPr}}$ & \multirow{2}{*}{\begin{tabular}{|l}
1 \\
$Z: E$
\end{tabular}} \\
\hline entry & $\mathrm{R}$ & $\mathrm{R}^{\prime}$ & RR'PH & $\begin{array}{l}\text { Major } \\
\text { Producta }\end{array}$ & $\begin{array}{c}\text { Conversion } \\
\%^{\mathrm{b}}\end{array}$ & \\
\hline 1 & $\mathrm{Ph}$ & Et & $\mathrm{PhPH}_{2}$ & \multirow[b]{2}{*}{$\mathrm{Ph} \quad \mathrm{PPhH}$} & 80 & $3: 1$ \\
\hline 2 & $\mathrm{Ph}$ & Et & $2 \mathrm{PhPH}_{2}$ & & 99 & $2.45: 1$ \\
\hline 3 & Et & Et & $\mathrm{PhPH}_{2}$ & \multirow{2}{*}{${ }^{E t}=\sum_{P P h H}^{E t}$} & 48 & $1: 1.7$ \\
\hline 4 & Et & Et & $2 \mathrm{PhPH}_{2}$ & & 71 & $1: 1.5$ \\
\hline 5 & $\mathrm{Ph}$ & $\mathrm{Ph}$ & $\mathrm{PhPH}_{2}$ & \multirow[b]{2}{*}{$\mathrm{Ph}=\mathrm{PPhH}$} & 40 & $1.9: 1$ \\
\hline 6 & $\mathrm{Ph}$ & $\mathrm{Ph}$ & $2 \mathrm{PhPH}_{2}$ & & 58 & $2.1: 1$ \\
\hline 7 & $\mathrm{Ph}$ & $\mathrm{H}$ & $2 \mathrm{PhPH}_{2}$ & \multirow[b]{2}{*}{$\mathrm{Ph} \quad \mathrm{Ph} \quad \mathrm{Ph}$} & $86^{c, d}$ & $3: 1^{\mathrm{e}}$ \\
\hline 8 & $\mathrm{Ph}$ & $\mathrm{H}$ & $0.5 \mathrm{PhPH}_{2}$ & & $88^{c, f}$ & $2.7: 1^{\mathrm{e}}$ \\
\hline 9 & $\mathrm{Ph}$ & Et & $\mathrm{Ph}_{2} \mathrm{PH}$ & & 74 & $4.8: 1$ \\
\hline 10 & $\mathrm{Ph}$ & $\mathrm{H}$ & $\mathrm{Ph}_{2} \mathrm{PH}$ & \multirow[b]{2}{*}{$\mathrm{Ph} \mathrm{PPh}_{2}$} & 41 & $32: 1$ \\
\hline 11 & $\mathrm{Ph}$ & $\mathrm{H}$ & $2 \mathrm{Ph}_{2} \mathrm{PH}$ & & 77 & $37.5: 1$ \\
\hline 12 & $\mathrm{Ph}$ & $\mathrm{Ph}$ & $\mathrm{Ph}_{2} \mathrm{PH}$ & \multirow[b]{3}{*}{$\mathrm{Ph}^{\prime} \quad \mathrm{PPh}_{2}$} & 12 & $1: 0$ \\
\hline $13 \mathrm{~g}$ & $\mathrm{Ph}$ & $\mathrm{Ph}$ & $\mathrm{Ph}_{2} \mathrm{PH}$ & & 11 & $10: 1$ \\
\hline 14 & $\mathrm{Ph}$ & $\mathrm{Ph}$ & $2 \mathrm{Ph}_{2} \mathrm{PH}$ & & $19^{d}\left(36^{\mathrm{h}}\right)$ & $35: 1^{\mathrm{h}}$ \\
\hline
\end{tabular}


Conditions: 0.38 mmol of alkyne and 0.38 or $0.76 \mathrm{mmol}$ of $\mathrm{PhPH}_{2}$ or $\mathrm{Ph}_{2} \mathrm{PH}$ and $0.019 \mathrm{mmol} \mathbf{1}$ [a] only the major stereoisomer is depicted [b] conversion to anti-markovnikov vinyl phosphine as determined by integration of ${ }^{1} \mathrm{H}$ and ${ }^{31} \mathrm{P}\left\{{ }^{1} \mathrm{H}\right\}$ NMR spectra [c] double $\mathrm{P}-\mathrm{H}$ bond activation product [d] $20 \mathrm{~h}$ [e] ratio of $Z, Z: E, Z$ product [f] $1 \mathrm{~h} \mathrm{[g]} 5 \mathrm{~mol}$ $\%$ of $\mathrm{PPh}_{3}$ added $[\mathrm{h}] 72 \mathrm{~h}$

\section{Benchmarking to the literature}

Benchmarking is an important endeavor in catalysis, 60 and among reports of copper-catalyzed hydrophosphination, ${ }^{12,32-34,61}$ Lipshutz's copper(II) acetate monohydrate, $\mathrm{Cu}(\mathrm{OAc}) \cdot{ }_{2} \mathrm{H}_{2} \mathrm{O}(2)$, stands out as highly active. ${ }^{34}$ That study focused on $\mathbf{2}$ in the catalytic hydrophosphination of styrene and $\alpha$-substituted styrene derivatives with $\mathrm{Ph}_{2} \mathrm{PH}$ in water utilizing the surfactant, TPGS-750-M. While water is a potentially attractive solvent, added surfactants are not, and to draw broader conclusions to the field, comparison reactions were run in $\mathrm{CDCl}_{3}$. A model of the literature reaction utilizing $5 \mathrm{~mol} \%$ of 2 , the same concentration of $\alpha$-methyl styrene $(0.25 \mathrm{mmol})$ and $\mathrm{Ph}_{2} \mathrm{PH}(0.375 \mathrm{mmol})$, and stirring under ambient light and temperatures, but substituting $\mathrm{CDCl}_{3}$ for a water/ TPGS-750-M mixture resulted in less than $25 \%$ conversion of $\alpha$ methyl styrene with diphenylphosphine in 20 h (Table 6, entry 1). This contrasts with 95\% conversion over the same time frame in water/ TPGS-750-M reported by Lipshutz (Table 6, entry 2). However, irradiation of a CDCl3 solution containing $\alpha$ methyl styrene, 1.5 equivalents of diphenylphosphine, and 5 mol \% of $\mathbf{2}$ in a J-Young type NMR tube resulted in a $76 \%$ conversion in $20 \mathrm{~h}$ (Table 6, entry 4). Irradiating a $\mathrm{CDCl}_{3}$ solution of $5 \mathrm{~mol} \%$ of $\mathbf{1}, \alpha$-methyl styrene, and 1.5 equivalents of diphenylphosphine under the same conditions resulted in $83 \%$ conversion after $20 \mathrm{~h}$ (Table 6, entry 5). Thus, for laboratories without access to TPGS-750-M, irradiating under $360 \mathrm{~nm}$ light in organic solvent or neat solution of $\mathbf{1}$ or $\mathbf{2}$ is a convenient alternative.

\section{Table 6. Benchmarking to the literature}

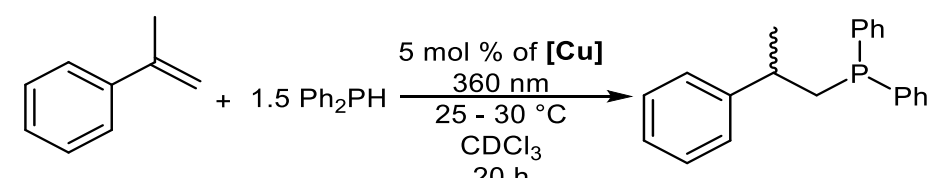

\begin{tabular}{|c|c|c|c|}
\hline Entry & Catalyst & $\begin{array}{c}\text { Conditions } \\
\text { (light; solvent; stirring) }\end{array}$ & $\begin{array}{c}\text { Conversion } \\
\%^{\mathrm{a}}\end{array}$ \\
\hline 1 & 2 & Ambient light; $\mathrm{CDCl}_{3}$; stirring & 25 \\
\hline 2 & 2 & $\begin{array}{l}\text { Ambient light; Water/TPG-750-M; } \\
\text { stirring }\end{array}$ & $95^{b}$ \\
\hline 3 & 2 & Ambient light; $\mathrm{CDCl}_{3}$ & $6^{c}$ \\
\hline 4 & 2 & $360 \mathrm{~nm} ; \mathrm{CDCl}_{3}$ & 76 \\
\hline 5 & 1 & $360 \mathrm{~nm} ; \mathrm{CDCl}_{3}$ & 83 \\
\hline
\end{tabular}

Conditions: $0.25 \mathrm{mmol}$ of alkene and $0.375 \mathrm{mmol}$ of phenylphosphine $0.0125 \mathrm{mmol}$ catalyst [a] conversion determined by integration of ${ }^{1} \mathrm{H}$ and ${ }^{31} \mathrm{P}\left\{{ }^{1} \mathrm{H}\right\}$ NMR spectra. [b] reported by Lipshutz. ${ }^{34}[\mathrm{c}] 17 \mathrm{~h}$ 
We also sought to benchmark under our conditions (Table 8). Interestingly, with primary phosphines, the activity of 2 appears to be slightly less active than $\mathbf{1}$, which is the opposite trend to what was observed with secondary phosphines. Treatment of styrene with 2 equiv. of phenylphosphine with 5 mol \% of 2 under what was otherwise our model photocatalytic conditions resulted in $86 \%$ conversion after $20 \mathrm{~min}$ (Table 8, entry 1), slightly less than the $100 \%$ conversion observed with 1 (Table 8, entry 2). Treatment of 1-hexene with 2 equiv. of phenylphosphine with 5 mol \% of 2 under what was otherwise our model photocatalytic conditions resulted in 68\% conversion after $24 \mathrm{~h}$ (Table 8, entry 3) vs 80\% conversion with 5 mol \% 1 over the same time period (Table 8, entry 4).

\section{Table 7. Comparison of 1 and 2 with primary phosphines}

\begin{tabular}{|c|c|c|c|c|c|}
\hline \multirow[b]{2}{*}{ Entry } & \multicolumn{2}{|c|}{$\mathrm{R} 刃+2 \mathrm{PhPH}_{2}$} & $\begin{array}{r}5 \mathrm{~mol} \% \text { of } \\
\frac{360 \mathrm{~nm}}{25-30^{\circ}} \\
\mathrm{CDCl}_{3}\end{array}$ & Cu] & \\
\hline & catalyst & Time & Alkene & Phosphine & $\begin{array}{c}\text { Conversion } \\
\%^{\mathrm{a}}\end{array}$ \\
\hline 1 & 2 & $20 \mathrm{~m}$ & styrene & $\mathrm{PhPH}_{2}$ & 86 \\
\hline 2 & 1 & $20 \mathrm{~m}$ & styrene & $\mathrm{PhPH}_{2}$ & 100 \\
\hline 3 & 2 & $20 \mathrm{~h}$ & 1-hexene & $\mathrm{PhPH}_{2}$ & 68 \\
\hline 4 & 1 & $20 \mathrm{~h}$ & 1-hexene & $\mathrm{PhPH}_{2}$ & 80 \\
\hline \multicolumn{6}{|c|}{$\begin{array}{l}\text { Conditions: } 0.38 \text { mmol of alkene and } 0.76 \text { mmol of phenylphosphine } \\
0.019 \text { mmol catalyst [a] conversion determined by integration }{ }^{1} \mathrm{H} \\
\text { and }{ }^{31} \mathrm{P}\left\{{ }^{1} \mathrm{H}\right\} \text { NMR spectra. For styrene this includes conversion to } \\
\text { both secondary and tertiary phosphines. }\end{array}$} \\
\hline
\end{tabular}

\section{Mechanistic insights}

Several lines of inquiry including, observation of modeled catalytic reactions, a comparison of copper precursors, isotope labeling experiments, stoichiometric model reactions, and a Hammett analysis in the context of the literature understanding of related copper catalysis provide a working mechanistic hypothesis.

In some examples, $\mathbf{1}$ is a precursor to copper oxide nanoparticles in the presence of organic molecules under thermal conditions. ${ }^{62,63}$ Several observations argue against this pathway. Previous reports of nanoparticle formation result in the formation of acetic acid and acetone byproducts that are not detected in this system. ${ }^{62}$ As a test of homogeneity of the active catalyst, $450 \mathrm{mg}$ of elemental mercury $(\mathrm{Hg})$ was added to the reaction of $\mathrm{Ph}_{2} \mathrm{PH}$ and styrene catalyzed by 5 mol $\%$ of $\mathbf{1}$ to sequester any precipitated copper.64 Observed reactivity was identical to reactions conducted without added Hg, suggesting that $\mathrm{Cu}(0)$ is not precipitating and is consistent with visual observation of a homogenous system. While these data are not definitive, they are consistent with molecular catalysis.

Radical reactivity is another possibility with redox active copper. As an initial test for radical reactivity, a reaction with two equivalents of phenylphosphine with styrene and $5 \mathrm{~mol} \%$ of 1 was conducted in the presence of 10 mol \% of 
2,2,6,6- tetramethylpiperidine-N-oxyl (TEMPO) ${ }^{64}$ under photocatalytic conditions. Observed reactivity was identical to the reaction conducted without TEMPO. The lack of inhibition from TEMPO is inconsistent with a radical based process. Additional study of this possibility is underway.

\section{Comparison of bis( $\beta$-diketonato) precursors}

To test the role of the $\beta$-diketonate ligand in the reaction, copper bis(2,2,6,6-tetramethyl-3,5-heptanedionate) (6) and copper bis(2,2,6,6-tetrafluoro-3,5-heptanedionate) (7) were synthesized and their reactivity explored (Table 6). When styrene was treated with 2 equiv. of phenylphosphine and 5 mol \% of 1 or 6 under photocatalytic conditions almost identical reactivity was observed and both catalysts gave quantitative conversion (Table 6, entry 1 and 2). Diminished reactivity was observed when this reaction was catalyzed with $5 \mathrm{~mol} \%$ of 7 , with only $30 \%$ conversion of styrene (Table 6 , entry 3) converted over the same reaction time. The same trend was observed in reactions with 1-hexene as greater than 70\% conversion was observed with both compound 1 (Table 6, entry 4) and 6 (Table 6, entry 5) compared to 44\% conversion with compound 7 (Table 6, entry 6). Additionally, ${ }^{1} \mathrm{H}$ NMR signals attributed to acetylacetone or 2,2,6,6tetramethyl-3,5-heptanedione were detected in reaction mixtures with $\mathbf{1}$ or $\mathbf{6}$. However, the corresponding $\beta$-diketone 1,1,1,5,5,5-hexafluoroacetylacetone was not observed in NMR spectra of reaction mixtures with 7 . Thus, it is likely that the decreased reactivity of $\mathbf{7}$ is a result of slower protonation of the less basic $\beta$-diketonate.

Table 8. Comparison of copper(II) bis( $\beta$-diketonato) precursors

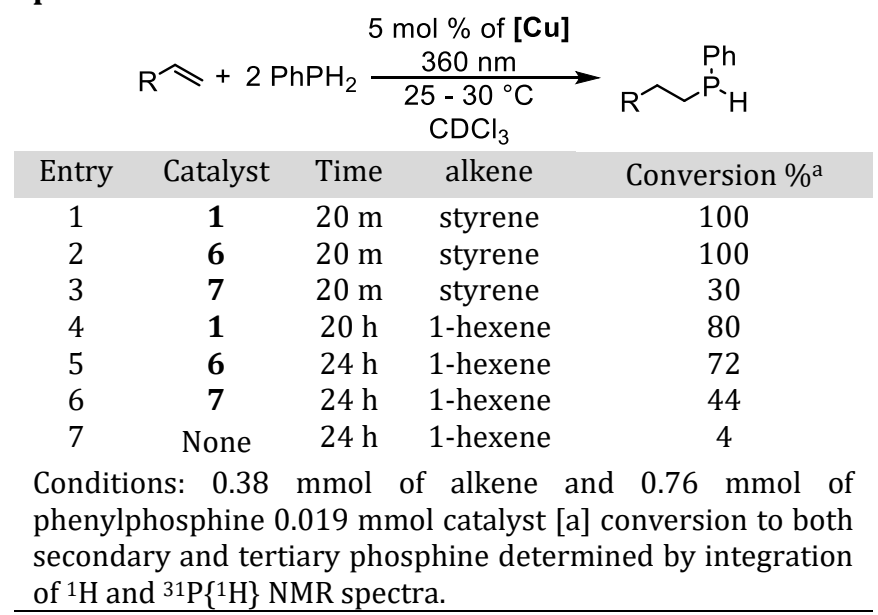<smiles></smiles>

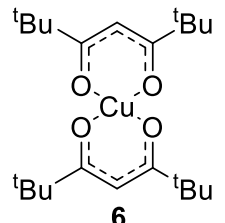<smiles>O=C(/C=C(\O[Ge])C(F)(F)F)C(F)(F)C(F)(F)F</smiles> 


\section{Catalyst activation}

To better understand the activation of $\mathbf{1}$, a systematic analysis of several parameters in the reaction was performed. Treatment of 5 mol \% of $\mathbf{1}$ with styrene resulted in no observable reactivity as determined by ${ }^{1} \mathrm{H}$ NMR spectroscopy. In contrast, treatment of $5 \mathrm{~mol} \%$ of $\mathbf{1}$ with $\mathrm{Ph}_{2} \mathrm{PH}$ resulted in the formation of acetylacetone and tetraphenyldiphosphine $\left(\mathrm{Ph}_{2} \mathrm{P}-\mathrm{PPh}_{2}\right.$, Scheme 2$)$ indicating that $\mathrm{P}-\mathrm{H}$ bond activation and formal protonation of 1 with release of acetylacetone are the initial steps in generating the catalytically active species. Importantly, quantitative activation of $\mathbf{1}$ is not immediate. An initial ${ }^{1} \mathrm{H}$ and ${ }^{31} \mathrm{P}\left\{{ }^{1} \mathrm{H}\right\}$ NMR spectrum of this reaction mixture demonstrated liberation of 0.45 equiv. of acetylacetone in a 1.55:1 ratio with $\mathrm{Ph}_{2} \mathrm{P}-\mathrm{PPh}_{2}$. This behavior indicates that several copper species that are potentially catalytically active may be generated. Irradiation of this sample over $3 \mathrm{~h}$ resulted in the continued increase in concentration of both products until 2 equiv. of acetylacetone were detected and $10 \%$ conversion of $\mathrm{Ph}_{2} \mathrm{PH}$ to $\mathrm{Ph}_{2} \mathrm{P}-\mathrm{PPh}_{2}$ had occurred. Continued irradiation of the sample beyond $3 \mathrm{~h}$ resulted in no change in the concentration of acetylacetone and only a small increase in the conversion of $\mathrm{Ph}_{2} \mathrm{PH}$ to $\mathrm{Ph}_{2} \mathrm{P}-\mathrm{PPh}$. When measured at $4 \mathrm{~h}, 15 \%$ conversion to $\mathrm{Ph}_{2} \mathrm{P}-\mathrm{PPh} 2$ had occurred and the signal for the $\mathrm{P}-\mathrm{H}$ bond of $\mathrm{Ph}_{2} \mathrm{PH}$ had broadened significantly in the ${ }^{1} \mathrm{H}$ NMR spectrum. At $20 \mathrm{~h}, 15 \%$ of $\mathrm{Ph}_{2} \mathrm{PH}$ had been consumed with an $11 \%$ conversion to $\mathrm{Ph}_{2} \mathrm{P}-\mathrm{PPh}_{2}$ along with and several decomposition products (See SI for a graph and further details). Glueck and coworker have previously observed that unidentified phosphine oxides are common in reactions of $\mathrm{Cu}(\mathrm{I})$ with phosphines, ${ }^{65}$ and similar byproducts are present in some hydrophosphination reactions

with 1. Repetition of this reaction with less solvent indicated that the complete activation of $\mathbf{1}$ is faster at higher concentrations of reactants and may account for the observed concentration dependence of catalysis (vide supra). Additionally, control reactions run in the dark demonstrate that both the formation of acetylacetone and $\mathrm{Ph}_{2} \mathrm{P}-\mathrm{PPh}_{2}$ proceeded faster under irradiation and may suggest one of the roles of light in this system. Furthermore, the correlation between the formation of acetylacetone and $\mathrm{Ph}_{2} \mathrm{P}-\mathrm{PPh}_{2}$ in these experiments suggest they are related processes.

The formation of $\mathrm{Ph}_{2} \mathrm{P}-\mathrm{PPh}_{2}$ could be through reductive elimination from a $\mathrm{Cu}(\mathrm{II})$ phosphido intermediate species as has been observed with other metals, ${ }^{2}$ a single electron transfer (SET) from $\mathrm{Ph}_{2} \mathrm{P}$ - to reduce $\mathbf{1}$ and subsequent coupling of two $\bullet \mathrm{PPh}_{2}$ radicals, or a bimetallic process. Regardless of pathway, literature and experimental observations point to generation of a $\mathrm{Cu}(\mathrm{I})$ species, 9, 11, 30,31,35, 58, 59, 65, 66, 67, 68 and reactions in the absence of unsaturated substrate implicate a copper phosphido intermediate in that process. 
Scheme 2: Reaction of 1 with 20 equiv. of diphenylphosphine

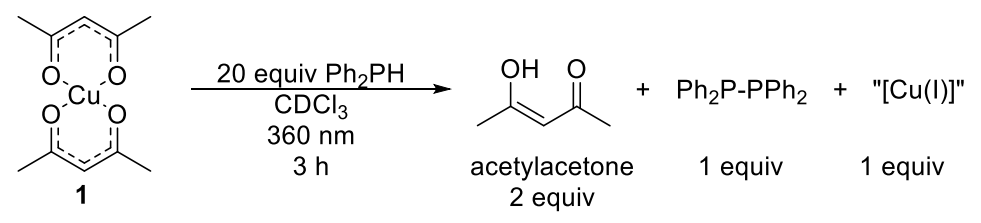

In Corma's study with $\mathrm{Cu}(\mathrm{OTf})_{2}$, a copper(I) active catalyst was proposed based on the observed loss of an EPR signal upon treating $\mathrm{Cu}(\mathrm{OTf})_{2}$ with $\mathrm{Ph}_{2} \mathrm{PH}$ among other results. ${ }^{12}$ Single electron transfer (SET) reductions of copper(II) compounds by electron rich substrates are well established, ${ }^{30,31}$ and precedent for the reduction of copper(II) $\beta$-diketones in the absence of a reducing agent comes from Tabacchi and others. ${ }^{66,67}$ Müller observed the in situ reduction of $\mathrm{Cu}(\mathrm{II})$ to $\mathrm{Cu}(\mathrm{I})$ in heterogeneous hydroamination reactions, and several groups have reported copper(I) hydride catalyzed hydrosilylation ${ }^{59,69}$ and hydroamination ${ }^{58}$ with 2 and a phosphine ligand upon the addition of a silane reductant.

\section{Reactivity of $\mathrm{Cu}(\mathrm{I})$ vs. $\mathrm{Cu}(\mathrm{II})$ precursors}

Tetrakis(acetonitrile)copper(I) hexafluorophosphate $\left(\left[\mathrm{Cu}\left(\mathrm{CH}_{3} \mathrm{CN}\right)_{4}\right] \mathrm{PF}_{6}, \quad 8\right)^{70} \operatorname{copper}(\mathrm{I})$ oxide $\left(\mathrm{Cu}_{2} \mathrm{O}, \quad 9\right)$, triphenylphosphine copper(I) hydride hexamer $\left(\left[\left(\mathrm{PPh}_{3}\right) \mathrm{CuH}\right]_{6}, \mathbf{1 0}\right)$, and a $\beta$-diketiminato copper(II) compound (11) were screened for differences in reactivity based on the formal oxidation state of copper. All catalysts tested were successful at catalyzing the hydrophosphination of styrene and phenylphosphine, at varying relative rates, under the same photocatalytic conditions (Table 7, entries 1-3). However, the same pattern was not observed for catalyzing 1-hexene and phenylphosphine. Copper(I) compounds 8, 9, and 10 were active with 1-hexene to various degrees (Table 7, entries 4-7) while 11 was inert to hydrophosphination of 1-hexene (Table 7, entry 8). This suggests copper(I) is more suited to that substrate and further points to an in-situ reduction of $\mathbf{1}$ (vide infra). Though not an ideal comparison due to the bulky 2,6diisopropylphenyl substituents of 11, the stronger chelation of the $\beta$-diketiminate of $\mathbf{1 1}$ compared to the more basic diketonate of $\mathbf{1}$ may prevent the reduction and account for the dramatic difference in reactivity between the two compounds. 
Table 9. Comparison of copper(I) and (II) precursors

\begin{tabular}{|c|c|c|c|c|c|}
\hline & $\mathrm{R} \curvearrowright+2 \mathrm{~F}$ & $\begin{array}{r}5 \mathrm{r} \\
\mathrm{H}_{2}\end{array}$ & $\begin{array}{l}\% \text { of [Cu] } \\
\frac{360 \mathrm{~nm}}{5-30{ }^{\circ} \mathrm{C}} \\
\mathrm{CDCl}_{3}\end{array}$ & $\widetilde{R}_{\dot{P}_{H}^{\mathrm{Ph}}}^{\mathrm{P}_{H}}$ & \\
\hline Entry & catalyst & Time & Alkene & Phosphine & Conversion $\%$ \\
\hline 1 & $\mathrm{Cu}\left(\mathrm{CH}_{3} \mathrm{CN}\right)_{4} \mathrm{PF}_{6}(\mathbf{8})$ & $20 \mathrm{~m}$ & styrene & $\mathrm{PhPH}_{2}$ & 45 \\
\hline 2 & $\mathrm{Cu}_{2} \mathrm{O}(9)$ & $20 \mathrm{~m}$ & styrene & $\mathrm{PhPH}_{2}$ & 15 \\
\hline 3 & {$\left[\left(\mathrm{PPh}_{3}\right) \mathrm{CuH}\right]_{6}(\mathbf{1 0})$} & $20 \mathrm{~m}$ & styrene & $\mathrm{PhPH}_{2}$ & 68 \\
\hline 4 & 11 & $20 \mathrm{~m}$ & styrene & $\mathrm{PhPH}_{2}$ & 41 \\
\hline 5 & 8 & $16 \mathrm{~h}$ & 1-hexene & $\mathrm{PhPH}_{2}$ & 26 \\
\hline 6 & 9 & $24 \mathrm{~h}$ & 1-hexene & $\mathrm{PhPH}_{2}$ & 73 \\
\hline 7 & 10 & $24 \mathrm{~h}$ & 1-hexene & $\mathrm{PhPH}_{2}$ & 70 \\
\hline 8 & 11 & $24 \mathrm{~h}$ & 1-hexene & $\mathrm{PhPH}_{2}$ & 1 \\
\hline 9 & 10 & $5 \mathrm{~h}$ & styrene & $\mathrm{Ph}_{2} \mathrm{PH}^{\mathrm{b}}$ & 78 \\
\hline Dinn & 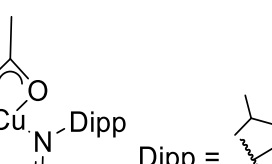 & $\begin{array}{l}\text { Co } \\
\mathrm{m} \\
{[\mathrm{a}} \\
\mathrm{an}\end{array}$ & $\begin{array}{l}\text { ditions: } 0.3 \\
\text { ol of phenyl } \\
\text { onversion } \\
{ }^{31} \mathrm{P}\left\{{ }^{1} \mathrm{H}\right\} \mathrm{NM}\end{array}$ & $\begin{array}{l}\text { mmol of } \\
\text { hosphine } 0.0 \\
\text { termined by } \\
\text { spectra. } 1\end{array}$ & $\begin{array}{l}\text { kene and } 0.76 \\
9 \text { mmol catalyst } \\
\text { ntegration of }{ }^{1} \mathrm{H}\end{array}$ \\
\hline
\end{tabular}

Copper(II) phosphido compounds are rare, ${ }^{71}$ and there are a limited number of copper(I) phosphido compounds known. ${ }^{33,48,72-76} 77$ Potentially related copper(I) phosphido compounds are $\left(\mathrm{PPh}_{3}\right) \mathrm{CuPPh} 2$ and $\left[\left(\mathrm{Ph}_{2} \mathrm{PH}\right) \mathrm{CuPPh}\right]_{n}$ reported by Caulton and coworkers. ${ }^{48}$ We were unable to prepare pure samples of $\left(\mathrm{PPh}_{3}\right) \mathrm{CuPPh}_{2}$ as reported for comparison. However, the similar reactivity between $\mathbf{1}$ and $\mathbf{1 0}$ is intriguing and was considered a proxy given that one route to $\left(\mathrm{PPh}_{3}\right)_{\mathrm{CuPPh}}$ is reaction of 9 with $\mathrm{Ph}_{2} \mathrm{PH}$. Furthermore, the observation that $\mathrm{PPh}_{3}$ did not negatively impact catalysis with $\mathbf{1}$ when added to reaction mixtures in several replicated reactions with both alkenes and alkynes is consistent with a $\mathrm{Cu}(\mathrm{I})$ phosphido intermediate. Though not isolated, $\left[\left(\mathrm{Ph}_{2} \mathrm{PH}\right) \mathrm{CuPPh}\right]_{n}$ was reported from the addition of multiple equivalents of $\mathrm{Ph}_{2} \mathrm{PH}$ to $\mathrm{Cu}\left(\mathrm{O}^{t} \mathrm{Bu}\right)_{4}$. Compound $\mathbf{1}$ when treated with one, two, four, eight and 20 equivalents of $\mathrm{Ph}_{2} \mathrm{PH}$ provided data consistent with observations made of $\left[\left(\mathrm{Ph}_{2} \mathrm{PH}\right) \mathrm{CuPPh}_{2}\right]_{n}$. A yellow solution was formed in these reactions with $J_{\mathrm{PH}}=311 \mathrm{~Hz}$, which compares favorably to the literature report. A similar trend was observed for the $\mathrm{Ph}_{2} \mathrm{PH}$ signal in the ${ }^{31} \mathrm{P}\left\{{ }^{1} \mathrm{H}\right\} \mathrm{NMR}$ spectra. The signal was shifted downfield when one equivalent of diphenylphosphine was added and the signal shifted back upfield toward the value of free diphenylphosphine as more $\mathrm{Ph}_{2} \mathrm{PH}$ was added to solution, as was seen in the literature. Attempts at crystalizing a discreet intermediate from these solutions resulted only in powders that were insoluble in common organic solvents, which was the purpose of adding $\mathrm{PPh}_{3}$ in the original study. Therefore, it is likely that akin to Caulton's report, an oligomeric or polymeric copper(I) phosphido can be formed under catalytic conditions. 


\section{Deuterium labeling experiments}

Deuterium labeling studies were undertaken to address the mechanism of $\mathrm{P}-\mathrm{C}$ bond formation. Styrene was treated with one equivalent of $\mathrm{Ph}_{2} \mathrm{PD}\left(71 \%\right.$ deuterium) and $5 \mathrm{~mol} \%$ of $\mathbf{1}$ under irradiation and monitored by ${ }^{1} \mathrm{H}$, ${ }^{2} \mathrm{H}$, and ${ }^{31} \mathrm{P}\left\{{ }^{1} \mathrm{H}\right\}$ NMR spectroscopy. Signals attributable to $58 \%$ deuterium incorporation at $\mathrm{C} 2$ (Scheme 4 ) of the hydrophosphination product as well as those at the oxygen and C3 of acetylacetone were observed (Scheme 4). Exchange was not detectable at any other positions of products. Multiple deuterium exchanges at acetylacetone indicate that there is more complex chemistry associated with this ligand. Importantly, it explains the lack of complete incorporation on the hydrophosphination product. The potential steps that would yield the isotopomers observed include a 2,1 insertion of styrene into a copper phosphido intermediate or a 1,2 insertion of alkene into a copper hydride intermediate. There is insufficient data to distinguish these possibilities.

\section{Scheme 4. Deuterium incorporation of hydrophosphination product and acetylacetone}

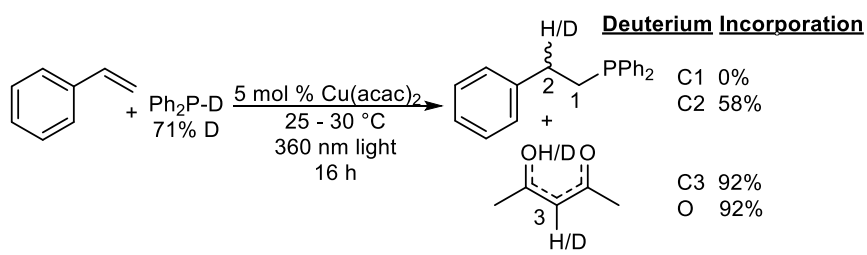

A Hammett analysis ${ }^{78}$ via competition experiment was performed to better understand electronic effects of the phosphine. Equimolar amounts of $\mathrm{Ph}_{2} \mathrm{PH}(0.5 \mathrm{eq})$ and $(4-\mathrm{MeOPh})_{2} \mathrm{PH}(0.5 \mathrm{eq})$ or $(4-\mathrm{MePh})_{2} \mathrm{PH}(0.5$ eq) were treated with 0.8 equiv. styrene as the limiting reagent with $5 \mathrm{~mol} \%$ of $\mathbf{1}$ under irradiation. The more electron rich and acidic (4$\mathrm{MeOPh})_{2} \mathrm{PH}$ underwent faster conversion and generated more of the hydrophosphination product. This indicates that acidity and/or nucleophilicity of the phosphine is important in catalysis.

A second Hammett analysis was performed to better understand electronic effects of the substrates in the reaction, which were not apparent from relative apparent rates (Scheme 5). In this experiment, the functional group on the para-positions of the unsaturated substrates were varied. A concave plot was observed. This behavior commonly indicates a change in mechanism upon introduction of different substituents, ${ }^{79}$ which helps explain the high activity of $\mathbf{1}$ towards both electron rich and poor unsaturated substrates. The high activity of $\mathbf{1}$ towards electron-poor substrates is consistent with nucleophilic attack of a copper phosphido on an unsaturated substrate, and is indeed the mechanism of most late metal hydrophosphination catalysts. ${ }^{2}$ However, the high activity of $\mathbf{1}$ towards unactivated substrates is inconsistent with a nucleophilic mechanism and argues for an insertion mechanism. Cui has previously proposed insertion of terminal alkynes into the $\mathrm{Cu}-\mathrm{P}$ bond of NHC-copper phosphido compounds. ${ }^{32}$ The Hammett data for our system may indicate that a 
nucleophilic mechanism is dominant with alkenes with electron withdrawing substituents and an insertion-based mechanism is predominant with electron donating substituents on styrene and with unactivated substrates.

\section{Figure 2. Hammett study of para-substituted styrene derivatives} and $\mathrm{PhPH}_{2}$ with 1
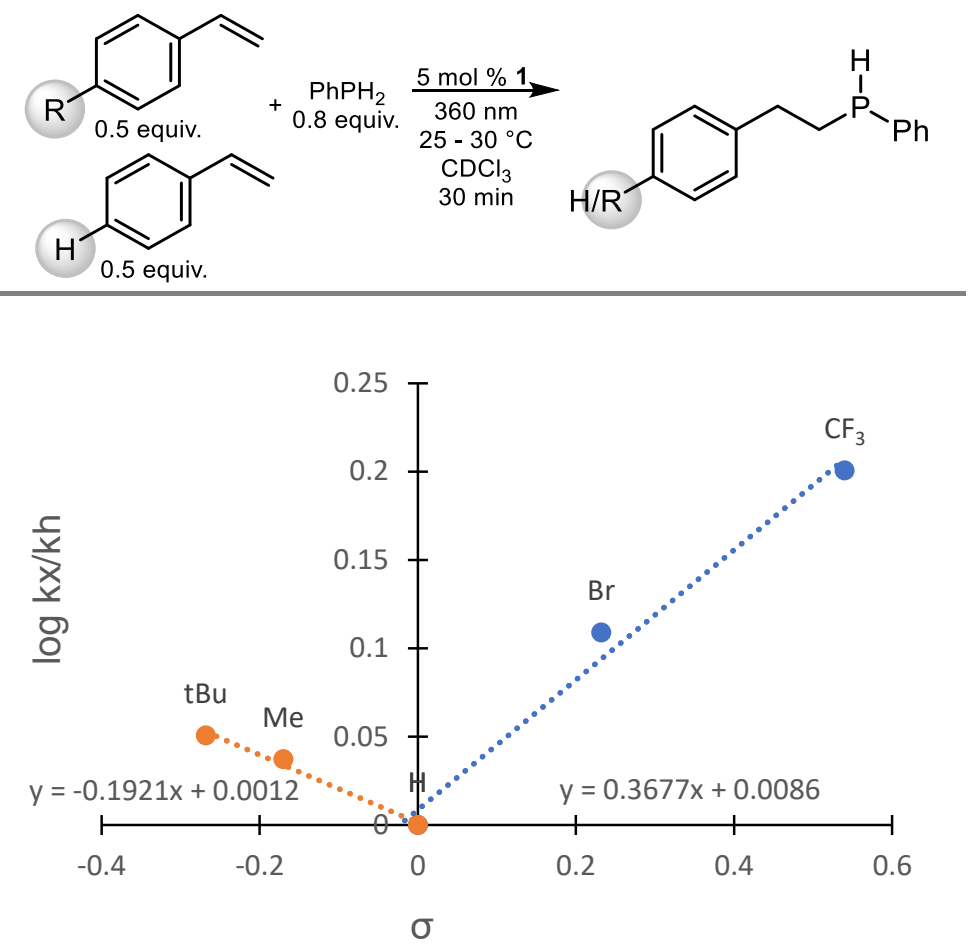

These data are informative but do not address the role of light in the reaction. For zirconium, evidence of a P $\mathrm{n} \rightarrow$ $\mathrm{Zr}$ d ligand-metal charge transfer that resulted in lengthening of the $\mathrm{Zr}-\mathrm{P}$ bond made substrate insertion more favorable was found. ${ }^{13}$ It is suspected that a charge transfer event is also responsible for the enhanced activity of $\mathbf{1}$ under photolysis, though promotion may be directly into a $\sigma^{*}$ orbital. The absence of a well-identified intermediate in this study make further analysis by computation too speculative for useful results. Nevertheless, this catalysis is clearly photocatalytic, and the yellow color of these reactions is indicative of an absorption that trails into the UV, which explains the effective $360 \mathrm{~nm}$ irradiation. However, without a discrete copper species isolated or identified, spectroscopic study of the absorption bands is complicated, and these conclusions are tenuous. Continued study of this phenomena is warranted and underway. For these reasons, and the uncertainties differentiating between 2,1 and 1,2 insertion presented above, a catalytic cycle would be too speculative to include in this report. However, these studies support redox activation of copper, formation of a copper- 
phosphido intermediate, and differential $\mathrm{P}-\mathrm{C}$ bond formation based on substrate, all of which are features that inform further catalyst development.

\section{Concluding Remarks}

Commercially available $\mathrm{Cu}(\mathrm{acac})_{2}(\mathbf{1})$ has been demonstrated to be a rapid and efficient hydrophosphination pre-catalyst for a diverse collection of phosphines and unsaturated substrates at ambient temperature under low intensity UV-A irradiation. This is the first report of an air- and water-stable compound capable of the catalytic hydrophosphination of unactivated substrates. Compound $\mathbf{1}$ is active with both primary and secondary phosphines, but significantly more so with the former, an underrepresented class of substrates. ${ }^{4}$ Both alkenes and alkynes are functionalized in this system, with 1 demonstrating greater activity with alkenes. Evidence points to a Cu(I) active species and either an insertion-based or nucleophilic pathway, depending on the nature of the unsaturated substrate. ${ }^{4}$ The success of irradiation of now copper and previously zirconium compounds supports photocatalysis as a general method for achieving highly active hydrophosphination catalysis. Additionally, this work further demonstrates that continued study of common laboratory reagents under new conditions, can yield new and exciting reactivity. ${ }^{80}$ Continued study of this system for mechanistic insight expansion of copper-catalyzed hydrophosphination is underway.

\section{Experimental Section}

General information

All manipulations were performed under a nitrogen atmosphere with dry, oxygen-free solvents using an M. Braun glovebox or standard Schlenk techniques unless otherwise noted. $\mathrm{CDCl}_{3}$ was purchased and then degassed and dried over calcium hydride and then distilled and stored over 3 and $4 \AA$ molecular sieves. Diphenylphosphine was synthesized according to literature procedures and stored under an inert atmosphere of $\mathrm{N}_{2}$ prior to use. ${ }^{81}$ Compounds $\mathbf{6}, 82 \mathbf{7 , 8 3} \mathbf{8 , 8 4} \mathbf{1 0}^{85}$ $\mathbf{1 1}^{86}$ and $\mathrm{Ph}_{2} \mathrm{PD}^{87}$ were synthesized according to literature procedures. All other reagents were acquired from commercial sources and dried by conventional means, as necessary. ESI-mass spectra were collected on an AB-Sciex 4000 QTrap Hybrid Triple Quadrupole/Linear Ion trap mass spectrometer. ${ }^{1} \mathrm{H},{ }^{2} \mathrm{H},{ }^{13} \mathrm{C},{ }^{31} \mathrm{P},{ }^{31} \mathrm{P}\left\{{ }^{1} \mathrm{H}\right\}$ and ${ }^{31} \mathrm{P}$ HMBC NMR spectra were recorded at $25^{\circ} \mathrm{C}$ with a Bruker AXR $500 \mathrm{MHz}$ or Varian $500 \mathrm{MHz}$ spectrometer.

Safety note: Phosphines are toxic, and many primary phosphines are volatile. Redox reactions or metal catalysts have the potential for rapid hydrogen evolution from phosphine substrates. Appropriate precautions for toxic gases and hydrogen are necessary in this work. 


\section{General procedure for catalytic experiments}

In an $\mathrm{N}_{2}$ filled dry box, $0.76 \mathrm{mmol}$ of phosphine (or $0.38 \mathrm{mmol}$ where applicable) and $0.38 \mathrm{mmol}$ of unsaturated substrate (and internal or external standard where applicable) were measured and mixed in $0.6 \mathrm{~mL} \mathrm{CDCl}_{3}$. This solution was either pipetted into a shell vial containing $0.019 \mathrm{mmol}$ of catalyst in $100 \mu \mathrm{L}$ of CDCL 3 or catalyst was added via stock solution. The resulting $6 \mathrm{~mL}$ solution was quickly transferred to either an aluminum foil wrapped J-Young type polytetrafluoroethylene-valved NMR tube or an NMR tube with a disposable NMR cap, which was subsequently wrapped with parafilm. For reactions containing an external standard, a sealed capillary containing 5 mg of $\mathrm{PPh}_{3}$ was added to the NMR tube before capping. Upon removal from dry box, the outside of the tube was washed with a 50:50 water: bleach to remove trace amounts of malodorous phosphine on the outside of the tube. An initial ${ }^{1} \mathrm{H}$ and ${ }^{31} \mathrm{P}\left\{{ }^{1} \mathrm{H}\right\}$ NMR spectra was then obtained as soon as possible. After the initial NMR spectra, reactions were removed from the aluminum foil and placed in a photoreactor containing a Rexim G23 UV-A (9W) lamp (unless otherwise noted) at ambient temperature and shielded from external light. Periodic ${ }^{1} \mathrm{H}$ and ${ }^{31} \mathrm{P}\left\{{ }^{1} \mathrm{H}\right\}$ NMR spectra were collected. Conversions were determined by integration of ${ }^{1} \mathrm{H}$ and ${ }^{31} \mathrm{P}\left\{{ }^{1} \mathrm{H}\right\}$ NMR spectra to starting materials and in many cases (see note in SI) confirmed by internal standard of either 1,3,5trimethoxy benzene, 25 tetramethyl silane, or an external standard of $\mathrm{PPh}_{3}$.

\section{Associated Content}

\section{Supporting Information}

The Supporting Information is available free of charge via the Internet at http://pubs.acs.org.

- Experimental procedures, spectroscopic data, supplementary figures and tables, and photographs and description of the photocatalysis reactor

\section{Author Information}

Corresponding Author

*Rory.Waterman@uvm.edu

\section{Acknowledgements}

This work was funded by U. S. National Science Foundation through CHE-1565658 and a graduate research fellowship for S. G. D. funded by the Vermont Space Grant Consortium under NASA Cooperative Agreement NNX15AP86H.

\section{Notes}

The authors declare no conflict of interest.

\section{References}

1. Gladysz, J. A.; Bedford, R. B.; Fujita, M.; Gabbaï, F. P.; Goldberg, K. I.; Holland, P. L.; Kiplinger, J. L.; Krische, M. J.; Louie, J.; Lu, C. C.; Norton, J. R.; Petrukhina, M. A.; Ren, T.; Stahl, S. S.; Tilley, T. D.; Webster, C. E.; White, M. C.; Whiteker, G. T., Organometallics Roundtable 2013-2014. Organometallics 2014, 33 (7), 1505-1527.

2. $\quad$ Rosenberg, L., Mechanisms of Metal-Catalyzed Hydrophosphination of Alkenes and Alkynes. ACS Catal. 2013, 3 (12), 2845-2855.

3. $\quad$ Corbridge, D. E. C., Phosphorus: Chemistry, Biochemistry and Technology, Sixth Edition. CRC Press: 2016.

4. Bange, C. A.; Waterman, R., Challenges in Catalytic Hydrophosphination. Chem. - Eur. J. 2016, 22 (36), 12598-12605.

5. Glueck, D. S., Metal-Catalyzed P-C Bond Formation via P-H Oxidative Addition: Fundamentals and Recent Advances. J. Org. Chem. 2020.

6. $\quad$ Glueck, D. S., Recent Advances in Metal-Catalyzed C-P Bond Formation. In $C-X$ Bond Formation, Vigalok, A., Ed. Springer Berlin Heidelberg: Berlin, Heidelberg, 2010; pp 65-100. 
7. Koshti, V.; Gaikwad, S.; Chikkali, S. H., Contemporary avenues in catalytic PH bond addition reaction: A case study of hydrophosphination. Coord. Chem. Rev. 2014, 265, 52-73.

8. Trnka, T. M.; Grubbs, R. H., The Development of L2X2RuCHR Olefin Metathesis Catalysts: An Organometallic Success Story. Acc. Chem. Res. 2001, 34 (1), 18-29.

9. $\quad$ Espinal-Viguri, M.; King, A. K.; Lowe, J. P.; Mahon, M. F.; Webster, R. L., Hydrophosphination of Unactivated Alkenes and Alkynes Using Iron(II): Catalysis and Mechanistic Insight. ACS Catal. 2016, 6 (11), 7892-7897.

10. Ji, P.; Sawano, T.; Lin, Z.; Urban, A.; Boures, D.; Lin, W., Cerium-Hydride Secondary Building Units in a Porous Metal-Organic Framework for Catalytic Hydroboration and Hydrophosphination. J. Am. Chem. Soc. 2016, 138 (45), 14860-14863.

11. Lapshin, I. V.; Yurova, O. S.; Basalov, I. V.; Rad'kov, V. Y.; Musina, E. I.; Cherkasov, A. V.; Fukin, G. K.; Karasik, A. A.; Trifonov, A. A., Amido $\mathrm{Ca}$ and $\mathrm{Yb}(\mathrm{II})$ Complexes Coordinated by Amidine-Amidopyridinate Ligands for Catalytic Intermolecular Olefin Hydrophosphination. Inorg. Chem. 2018, 57 (5), 2942-2952.

12. Leyva-Pérez, A.; Vidal-Moya, J. A.; Cabrero-Antonino, J. R.; Al-Deyab, S. S.; Al-Resayes, S. I.; Corma, A., Copper(I)catalyzed hydrophosphination of styrenes. J. Organomet. Chem. 2011, 696 (1), 362-367.

13. Bange, C. A.; Conger, M. A.; Novas, B. T.; Young, E. R.; Liptak, M. D.; Waterman, R., Light-Driven, ZirconiumCatalyzed Hydrophosphination with Primary Phosphines. ACS Catal. 2018, 8 (7), 6230-6238.

14. Novas, B. T.; Bange, C. A.; Waterman, R., Photocatalytic Hydrophosphination of Alkenes and Alkynes Using Diphenylphosphine and Triamidoamine-Supported Zirconium. Eur. J. Inorg. Chem. 2019, 2019 (11-12), 1640-1643.

15. Waterman, R., Triamidoamine-Supported Zirconium Compounds in Main Group Bond-Formation Catalysis. Acc. Chem. Res. 2019, 52 (8), 2361-2369.

16. Ghebreab, M. B.; Bange, C. A.; Waterman, R., Intermolecular Zirconium-Catalyzed Hydrophosphination of Alkenes and Dienes with Primary Phosphines. J. Am. Chem. Soc. 2014, 136 (26), 9240-9243.

17. Chapple, P. M.; Kahlal, S.; Cartron, J.; Roisnel, T.; Dorcet, V.; Cordier, M.; Saillard, J. Y.; Carpentier, J. F.; Sarazin, Y., Bis(imino)carbazolate: A Master Key for Barium Chemistry. Angew. Chem., Int. Ed. 2020, 59 (23), 9120-9126.

18. Basalov, I. V.; Dorcet, V.; Fukin, G. K.; Carpentier, J.-F.; Sarazin, Y.; Trifonov, A. A., Highly Active, Chemo- and Regioselective YbII and SmII Catalysts for the Hydrophosphination of Styrene with Phenylphosphine. Chem. - Eur. J. 2015, 21 (16), 6033-6036.

19. Selikhov, A. N.; Plankin, G. S.; Cherkasov, A. V.; Shavyrin, A. S.; Louyriac, E.; Maron, L.; Trifonov, A. A., Thermally Stable $\mathrm{Ln}(\mathrm{II})$ and $\mathrm{Ca}(\mathrm{II})$ Bis(benzhydryl) Complexes: Excellent Precatalysts for Intermolecular Hydrophosphination of C-C Multiple Bonds. Inorg. Chem. 2019, 58 (8), 5325-5334.

20. $\mathrm{Hu}, \mathrm{H}$.; Cui, C., Synthesis of Calcium and Ytterbium Complexes Supported by a Tridentate Imino-Amidinate Ligand and Their Application in the Intermolecular Hydrophosphination of Alkenes and Alkynes. Organometallics 2012, 31 (3), $1208-1211$.

21. A search of Sigma Aldrich on 2/10/20 reflected the lowest price per gram of $98 \% \mathrm{PPh}_{2} \mathrm{H}$ at $\$ 2.73 / \mathrm{g}$ compared to $\$ 35.4 /$ gram for $98 \%$ purity $\mathrm{OPPh}_{2} \mathrm{H}$.

22. Ackley, B. J.; Pagano, J. K.; Waterman, R., Visible-light and thermal driven double hydrophosphination of terminal alkynes using a commercially available iron compound. Chem. Commun. (Cambridge, U. K.) 2018, 54 (22), $2774-2776$.

23. Pagano, J. K.; Bange, C. A.; Farmiloe, S. E.; Waterman, R., Visible Light Photocatalysis Using a Commercially Available Iron Compound. Organometallics 2017, 36 (20), 3891-3895.

24. Routaboul, L.; Toulgoat, F.; Gatignol, J.; Lohier, J.-F.; Norah, B.; Delacroix, O.; Alayrac, C.; Taillefer, M.; Gaumont, A.-C., Iron-Salt-Promoted Highly Regioselective $\alpha$ and $\beta$ Hydrophosphination of Alkenyl Arenes. Chem. - Eur. J. 2013, 19 (27), 8760-8764.

25. King, A. K.; Gallagher, K. J.; Mahon, M. F.; Webster, R. L., Markovnikov versus anti-Markovnikov Hydrophosphination: Divergent Reactivity Using an Iron(II) $\beta$-Diketiminate Pre-Catalyst. Chem. - Eur. J. 2017, 23 (38), $9039-$ 9043.

26. Kamitani, M.; Itazaki, M.; Tamiya, C.; Nakazawa, H., Regioselective double hydrophosphination of terminal arylacetylenes catalyzed by an iron complex. J. Am. Chem. Soc. 2012, 134 (29), 11932-5.

27. Itazaki, M.; Katsube, S.; Kamitani, M.; Nakazawa, H., Synthesis of vinylphosphines and unsymmetric diphosphines: iron-catalyzed selective hydrophosphination reaction of alkynes and vinylphosphines with secondary phosphines. Chem. Commun. (Cambridge, U. K.) 2016, 52 (15), 3163-6.

28. Pritzwald-Stegmann, J. R.; Lonnecke, P.; Hey-Hawkins, E., Hydrophosphination reactions with transition metal ferrocenylphosphine complexes. Dalton Trans. 2016, 45 (5), 2208-17.

29. Gallagher, K. J.; Espinal-Viguri, M.; Mahon, M. F.; Webster, R. L., A Study of Two Highly Active, Air-Stable Iron(III)$\mu$-Oxo Precatalysts: Synthetic Scope of Hydrophosphination using Phenyl- and Diphenylphosphine. Adv. Synth. Catal. 2016, 358 (15), 2460-2468.

30. Zhang, C.; Tang, C.; Jiao, N., Recent advances in copper-catalyzed dehydrogenative functionalization via a single electron transfer (SET) process. Chem. Soc. Rev. 2012, 41 (9), 3464-3484.

31. McCann, S. D.; Stahl, S. S., Copper-Catalyzed Aerobic Oxidations of Organic Molecules: Pathways for Two-Electron Oxidation with a Four-Electron Oxidant and a One-Electron Redox-Active Catalyst. Acc. Chem. Res. 2015, 48 (6), $1756-1766$.

32. Kondoh, A.; Yorimitsu, H.; Oshima, K., Copper-Catalyzed anti-Hydrophosphination Reaction of 1-Alkynylphosphines with Diphenylphosphine Providing (Z)-1,2-Diphosphino-1-alkenes. J. Am. Chem. Soc. 2007, 129 (13), 4099-4104.

33. Yuan, J.; Zhu, L.; Zhang, J.; Li, J.; Cui, C., Sequential Addition of Phosphine to Alkynes for the Selective Synthesis of 1,2-Diphosphinoethanes under Catalysis. Well-Defined NHC-Copper Phosphides vs in Situ CuCl2/NHC Catalyst. Organometallics 2017, $36(2), 455-459$. 
34. Isley, N.; Linstadt, R.; D Slack, E.; Lipshutz, B., Copper-catalyzed hydrophosphinations of styrenes in water at room temperature. Dalton Trans. 2014, 43.

35. Shafir, A.; Buchwald, S. L., Highly Selective Room-Temperature Copper-Catalyzed C-N Coupling Reactions. J. Am. Chem. Soc. 2006, 128 (27), 8742-8743.

36. Kang, S.-K.; Lee, S.-H.; Lee, D., Copper-Catalyzed N-Arylation of Amines with Hypervalent Iodonium Salts. Synlett 2000, 2000 (07), 1022-1024.

37. Kawano, T.; Hirano, K.; Satoh, T.; Miura, M., A New Entry of Amination Reagents for Heteroaromatic C-H Bonds: Copper-Catalyzed Direct Amination of Azoles with Chloroamines at Room Temperature. J. Am. Chem. Soc. 2010, 132 (20), 69006901 .

38. Wagh, Y. S.; Bhanage, B. M., Cu(acac) 2 catalyzed oxidative $\mathrm{C}-\mathrm{H}$ bond amination of azoles with amines under base-free conditions. Tetrahedron Lett. 2012, 53 (48), 6500-6503.

39. Krajewski, S. M.; Crossman, A. S.; Akturk, E. S.; Suhrbier, T.; Scappaticci, S. J.; Staab, M. W.; Marshak, M. P., Sterically encumbered $\beta$-diketonates and base metal catalysis. Dalton Trans. 2019, 48 (28), 10714-10722.

40. Trostyanskaya, I. G.; Beletskaya, I. P., Copper (II)-catalyzed regio- and stereoselective addition of H/P(O)R2 to alkynes. Tetrahedron 2014, 70 (15), 2556-2562.

41. Bissessar, D.; Egly, J.; Achard, T.; Steffanut, P.; Bellemin-Laponnaz, S., Catalyst-free hydrophosphination of alkenes in presence of 2-methyltetrahydrofuran: a green and easy access to a wide range of tertiary phosphines. $R S C A d v .2019,9$ (47), $27250-27256$.

42. Tolpygin, A. O.; Cherkasov, A. V.; Fukin, G. K.; Kovylina, T. A.; Lyssenko, K. A.; Trifonov, A. A., Calcium Amido Complexes Coordinated by Tridentate Amidinate Ligands: Synthesis, Structures and Catalytic Activity in Olefin Hydrophosphination and Polymerization of Cyclic Esters. Eur. J. Inorg. Chem. 2019, 2019 (39-40), 4289-4296.

43. Pollard, V. A.; Young, A.; McLellan, R.; Kennedy, A. R.; Tuttle, T.; Mulvey, R. E., Lithium-Aluminate-Catalyzed Hydrophosphination Applications. Angew. Chem., Int. Ed. 2019, 58 (35), 12291-12296.

44. Zhang, Y.; Qu, L.; Wang, Y.; Yuan, D.; Yao, Y.; Shen, Q., Neutral and Cationic Zirconium Complexes Bearing Multidentate Aminophenolato Ligands for Hydrophosphination Reactions of Alkenes and Heterocumulenes. Inorg. Chem. 2018, 57 (1), 139-149.

45. $\quad$ King, A. K.; Buchard, A.; Mahon, M. F.; Webster, R. L., Facile, Catalytic Dehydrocoupling of Phosphines Using $\beta$ Diketiminate Iron(II) Complexes. Chem. - Eur. J. 2015, 21 (45), 15960-15963.

46. Cibuzar, M. P.; Dannenberg, S. G.; Waterman, R., A Commercially Available Ruthenium Compound for Catalytic Hydrophosphination. Isr. J. Chem. 2019, 60 (3-4), 446-451.

47. Bezman, S. A.; Churchill, M. R.; Osborn, J. A.; Wormald, J., Preparation and crystallographic characterization of a hexameric triphenylphosphinecopper hydride cluster. J. Am. Chem. Soc. 1971, 93 (8), 2063-2065.

48. Lemmen, T. H.; Goeden, G. V.; Huffman, J. C.; Geerts, R. L.; Caulton, K. G., Alcohol elimination chemistry of tetrakis(tert-butoxocopper). Inorg. Chem. 1990, 29 (19), 3680-3685.

49. Garner, M. E.; Parker, B. F.; Hohloch, S.; Bergman, R. G.; Arnold, J., Thorium Metallacycle Facilitates Catalytic Alkyne Hydrophosphination. J. Am. Chem. Soc. 2017, 139 (37), 12935-12938.

50. Yang, Y.; Shi, S.-L.; Niu, D.; Liu, P.; Buchwald, S. L., Catalytic asymmetric hydroamination of unactivated internal olefins to aliphatic amines. Science 2015, 349 (6243), 62-66.

51. Chadwick, A. C.; Heckenast, M. A.; Race, J. J.; Pringle, P. G.; Sparkes, H. A., Self-Replication of Chelating Diphosphines via Pt(0)-Catalyzed Hydrophosphination. Organometallics 2019, 38 (19), 3871-3879.

52. Zhang, Y.; Wang, X.; Wang, Y.; Yuan, D.; Yao, Y., Hydrophosphination of alkenes and alkynes with primary phosphines catalyzed by zirconium complexes bearing aminophenolato ligands. Dalton Trans. 2018, 47 (27), 9090-9095.

53. Bange, C. A.; Waterman, R., Zirconium-Catalyzed Intermolecular Double Hydrophosphination of Alkynes with a Primary Phosphine. ACS Catal. 2016, 6 (10), 6413-6416.

54. Di Giuseppe, A.; De Luca, R.; Castarlenas, R.; Pérez-Torrente, J. J.; Crucianelli, M.; Oro, L. A., Double hydrophosphination of alkynes promoted by rhodium: the key role of an N-heterocyclic carbene ligand. Chem. Commun. (Cambridge, U. K.) 2016, 52 (32), 5554-5557.

55. Kamitani, M.; Itazaki, M.; Tamiya, C.; Nakazawa, H., Regioselective double hydrophosphination of terminal arylacetylenes catalyzed by an iron complex. J. Am. Chem. Soc. 2012, 134 (29), 11932.

56. Yao, W.; Ma, M.; Zhang, N.; Li, Y.; Pullarkat, S. A.; Leung, P.-H., Palladacyclo-promoted asymmetric hydrophosphination reaction between diphenylphosphine and 2-ethynylpyridine. J. Organomet. Chem. 2016, 801, 1-5.

57. Basiouny, M. M. I.; Dollard, D. A.; Schmidt, J. A. R., Regioselective Single and Double Hydrophosphination and Hydrophosphinylation of Unactivated Alkynes. ACS Catal. 2019, 9 (8), 7143-7153.

58. Bandar, J. S.; Pirnot, M. T.; Buchwald, S. L., Mechanistic Studies Lead to Dramatically Improved Reaction Conditions for the Cu-Catalyzed Asymmetric Hydroamination of Olefins. J. Am. Chem. Soc. 2015, 137 (46), 14812-14818.

59. Lipshutz, B. H.; Frieman, B. A., CuH in a bottle: a convenient reagent for asymmetric hydrosilylations. Angew. Chem., Int. Ed. 2005, 44 (39), 6345-8.

60. Bligaard, T.; Bullock, R. M.; Campbell, C. T.; Chen, J. G.; Gates, B. C.; Gorte, R. J.; Jones, C. W.; Jones, W. D.; Kitchin, J. R.; Scott, S. L., Toward Benchmarking in Catalysis Science: Best Practices, Challenges, and Opportunities. ACS Catal. 2016, 6 (4), 2590-2602.

61. Yue, W.-J.; Xiao, J.-Z.; Zhang, S.; Yin, L., Rapid Synthesis of Chiral 1,2-Bisphosphine Derivatives through Copper(I)Catalyzed Asymmetric Conjugate Hydrophosphination. Angew. Chem., Int. Ed. 2020, 59 (18), 7057-7062. 
62. Staniuk, M.; Zindel, D.; van Beek, W.; Hirsch, O.; Kränzlin, N.; Niederberger, M.; Koziej, D., Matching the organic and inorganic counterparts during nucleation and growth of copper-based nanoparticles - in situ spectroscopic studies. CrystEngComm 2015, 17 (36), 6962-6971.

63. Nasibulin, A. G.; Kauppinen, E. I.; Brown, D. P.; Jokiniemi, J. K., Nanoparticle Formation via Copper (II) Acetylacetonate Vapor Decomposition in the Presence of Hydrogen and Water. J. Phys. Chem. B 2001, 105 (45), 11067-11075.

64. Meek, S. J.; Pitman, C. L.; Miller, A. J. M., Deducing Reaction Mechanism: A Guide for Students, Researchers, and Instructors. J. Chem. Educ. 2016, 93 (2), 275-286.

65. Gibbons, S. K.; D. Valleau, C. R.; Peltier, J. L.; Cain, M. F.; Hughes, R. P.; Glueck, D. S.; Golen, J. A.; Rheingold, A. L., Diastereoselective Coordination of P-Stereogenic Secondary Phosphines in Copper(I) Chiral Bis(phosphine) Complexes: Structure, Dynamics, and Generation of Phosphido Complexes. Inorg. Chem. 2019, 58 (13), 8854-8865.

66. Barreca, D.; Fois, E.; Gasparotto, A.; Seraglia, R.; Tondello, E.; Tabacchi, G., How Does CuII Convert into CuI? An Unexpected Ring-Mediated Single-Electron Reduction. Chem. - Eur. J. 2011, 17 (39), 10864-10870.

67. Mack, D. J.; Njardarson, J. T., New mechanistic insights into the copper catalyzed ring expansion of vinyl aziridines: evidence in support of a copper(i) mediated pathway. Chem. Sci. 2012, 3 (11), 3321-3325.

68. Yi, H.; Yang, D.; Luo, Y.; Pao, C.-W.; Lee, J.-F.; Lei, A., Direct Observation of Reduction of Cu(II) to Cu(I) by P-H Compounds using XAS and EPR Spectroscopy. Organometallics 2016, 35 (10), 1426-1429.

69. Lee, D.-w.; Yun, J., Copper-catalyzed asymmetric hydrosilylation of ketones using air and moisture stable precatalyst $\mathrm{Cu}(\mathrm{OAc}) 2 \cdot \mathrm{H} 2 \mathrm{O}$. Tetrahedron Lett. 2004, 45 (28), 5415-5417.

70. While this manuscript was in preparation, this compound with added base was reported by the group of Yin for the generation of assymetric bisphosphine derivatives via hydrophosphination in reference 61.

71. Mankad, N. P.; Rivard, E.; Harkins, S. B.; Peters, J. C., Structural Snapshots of a Flexible Cu2P2 Core that Accommodates the Oxidation States CuICuI, Cu1.5Cu1.5, and CuIICuII. J. Am. Chem. Soc. 2005, 127 (46), 16032-16033.

72. Wang, G.; Gibbons, S. K.; Glueck, D. S.; Sibbald, C.; Fleming, J. T.; Higham, L. J.; Rheingold, A. L., CopperPhosphido Intermediates in $\mathrm{Cu}(\mathrm{IPr})$-Catalyzed Synthesis of 1-Phosphapyracenes via Tandem Alkylation/Arylation of Primary Phosphines. Organometallics 2018, 37 (11), 1760-1772.

73. $\quad$ Cain, M. F.; Hughes, R. P.; Glueck, D. S.; Golen, J. A.; Moore, C. E.; Rheingold, A. L., Synthesis and Structure of Intermediates in Copper-Catalyzed Alkylation of Diphenylphosphine. Inorg. Chem. 2010, 49 (17), 7650-7662.

74. Fortman, G. C.; Slawin, A. M. Z.; Nolan, S. P., A Versatile Cuprous Synthon: $[\mathrm{Cu}(\operatorname{IPr})(\mathrm{OH})](\mathrm{IPr}=1,3$ bis(diisopropylphenyl)imidazol-2-ylidene). Organometallics 2010, 29 (17), 3966-3972.

75. Hill, T., Crystal structure of phosphido-tris-(triphenylphosphine)copper(I)acetone solvate, C57H51CuOP4. Z. Kristallogr. NCS 2013, 228, 120-122.

76. Khalili Najafabadi, B.; Corrigan, J. F., Enhanced thermal stability of $\mathrm{Cu}$-silylphosphido complexes via NHC ligation. Dalton Trans. 2015, 44 (32), 14235-14241.

77. Okugawa, Y.; Hirano, K.; Miura, M., Copper-Catalyzed Vicinal Diphosphination of Styrenes: Access to 1,2Bis(diphenylphosphino)ethane-Type Bidentate Ligands from Olefins. Angew. Chem., Int. Ed. 2016, 55 (43), $13558-13561$.

78. Mullins, R. J.; Vedernikov, A.; Viswanathan, R., Competition Experiments as a Means of Evaluating Linear Free Energy Relationships. An Experiment for the Advanced Undergraduate Organic Chemistry Lab. J. Chem. Educ. 2004,81 (9), 1357.

79. Lee, D. G.; Congson, L. N., Kinetics and mechanism of the oxidation of alcohols by ruthenate and perruthenate ions. Can. J. Chem. 1990, 68 (10), 1774-1779.

80. Hood, D. M.; Johnson, R. A.; Carpenter, A. E.; Younker, J. M.; Vinyard, D. J.; Stanley, G. G., Highly active cationic cobalt(II) hydroformylation catalysts. Science 2020, 367 (6477), 542-548.

81. Gulyás, H.; Benet-Buchholz, J.; Escudero-Adan, E. C.; Freixa, Z.; van Leeuwen, P. W. N. M., Ionic Interaction as a Powerful Driving Force for the Formation of Heterobidentate Assembly Ligands. Chem. - Eur. J. 2007, 13 (12), $3424-3430$.

82. Tambade, P.; Patil, Y.; Nandurkar, N.; Bhanage, B., Copper-Catalyzed, Palladium-Free Carbonylative Sonogashira Coupling Reaction of Aliphatic and Aromatic Alkynes with Iodoaryls. Synlett 2008, 2008, 886-888.

83. Chiyindiko, E.; Conradie, J., Redox behaviour of bis( $\beta$-diketonato)copper(II) complexes. J. Electroanal. Chem. 2019, $837,76-85$.

84. Kubas, G. J.; Monzyk, B.; Crumblis, A. L., Tetrakis(Acetonitrile)Copper(1+) Hexafluorophosphate(1-). In Inorg. Synth., 2007; pp 68-70.

85. Paterson, I.; Fink, S. J.; Lee, L. Y. W.; Atkinson, S. J.; Blakey, S. B., Total Synthesis of Aplyronine C. Org. Lett. 2013, 15 (12), 3118-3121.

86. Azoulay, J. D.; Rojas, R. S.; Serrano, A. V.; Ohtaki, H.; Galland, G. B.; Wu, G.; Bazan, G. C., Nickel $\alpha-$ Keto- $\beta$ Diimine Initiators for Olefin Polymerization. Angew. Chem., Int. Ed. 2009, 48 (6), 1089-1092.

87. Schmidt, A.; Nödling, A. R.; Hilt, G., An Alternative Mechanism for the Cobalt-Catalyzed Isomerization of Terminal Alkenes to (Z)-2-Alkenes. Angew. Chem., Int. Ed. 2015, 54 (3), 801-804. 


\section{Table of Contents artwork}

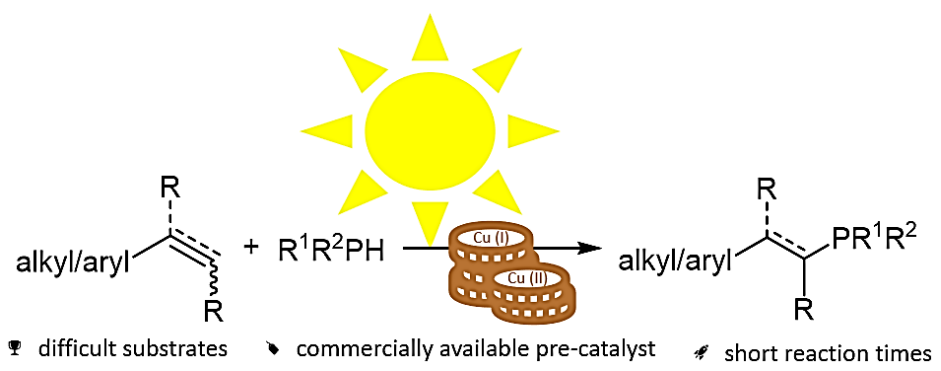

